Document downloaded from:

http://hdl.handle.net/10251/154040

This paper must be cited as:

Payri, R.; Gimeno, J.; Cardona-Vargas, S.; Ayyapureddi, S. (2019). Experimental study of the influence of the fuel and boundary conditions over the soot formation in multi-hole diesel injectors using high-speed color diffused back-illumination technique. Applied Thermal Engineering. 158:1-16. https://doi.org/10.1016/j.applthermaleng.2019.113746

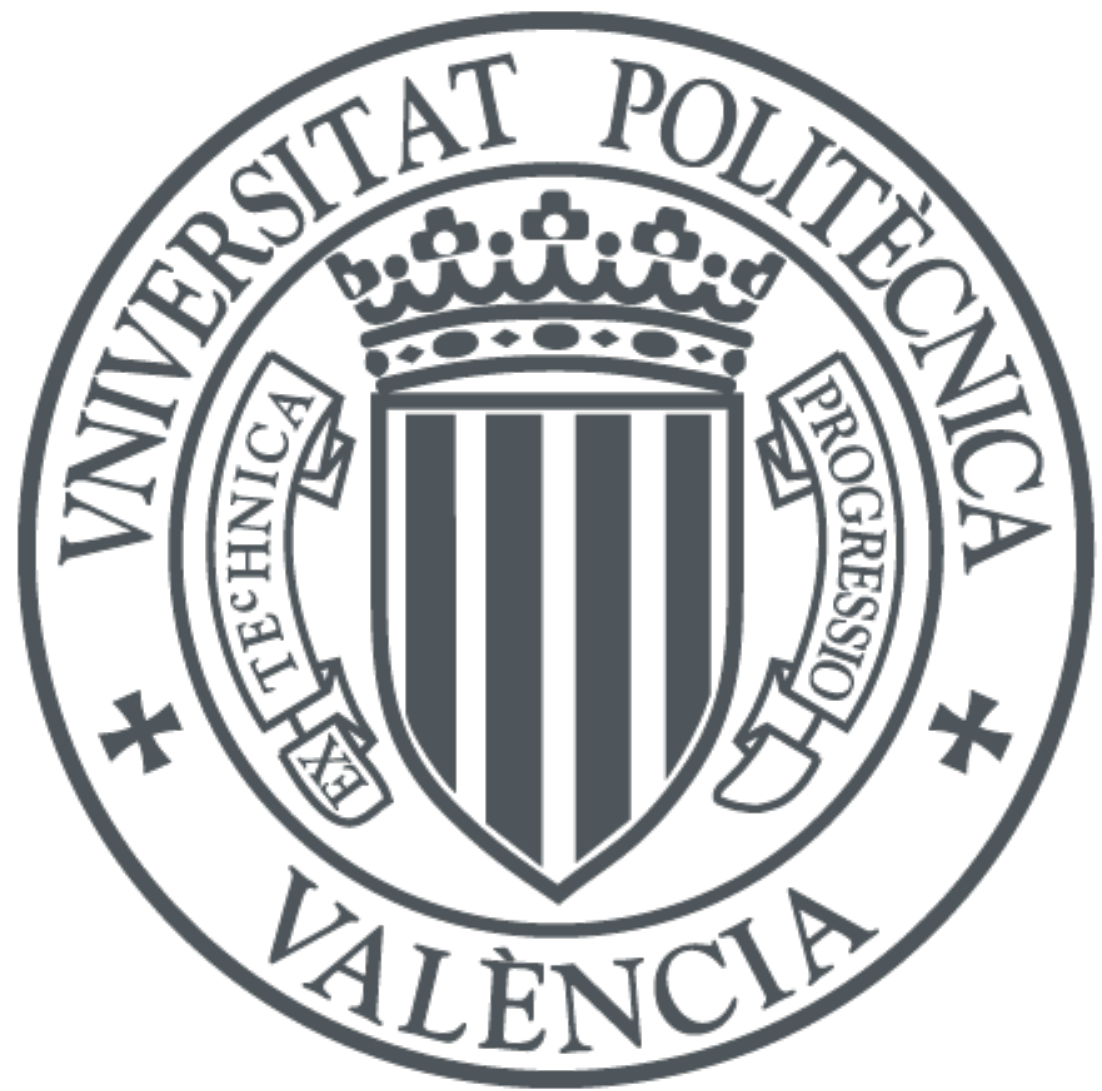

The final publication is available at

https://doi.org/10.1016/j.applthermaleng.2019.113746

Copyright Elsevier

Additional Information 


\title{
Experimental study of the influence of the fuel and boundary conditions over the soot formation in multi-hole diesel injectors using high-speed color diffused back illumination technique.
}

\author{
Raul Payri ${ }^{\mathrm{a}, *}$, Jaime Gimeno ${ }^{\mathrm{a}}$, Santiago Cardona ${ }^{\mathrm{a}}$, Sridhar Ayyapureddi ${ }^{\mathrm{b}}$ \\ ${ }^{a} C M T$ - Motores Térmicos, Camino de Vera (s/n), Universitat Politècnica de València, Edificio $6 D$, 46022, Valencia, Spain. \\ b faguar Land Rover Ltd, Abbey Road, Whitley, CV3 4LF Coventry, UK
}

\begin{abstract}
Two prototypes multi-hole diesel injector from a high-pressure common rail system were used to operated with diesel and n-Heptane fuels in a high-pressure and high-temperature test rig able to reach 1100 Kelvin and $15 \mathrm{MPa}$ under different oxygen concentrations with the goal to study the influence of the boundary conditions on the combustion process evaluating parameters as ignition delay, lift-off length and soot formation. A novel optical set-up was implemented to visualize the soot cloud evolution in the fuel jet between 30 to 85 millimeters from the nozzle exit using the high-speed color diffused back illumination technique, it was used as a result of the insertion of a high-pressure window in the injector holder opposite to the frontal window of the vessel allowing an optical arrangement in line-of-sight. The experiments performed in this work used a LED with a wavelength of $460 \mathrm{~nm}$ to provide information about physical of the soot properties, the results of varying the operational conditions show the reduction of soot formation with an increase in injection pressure, a reduction in ambient temperature, a reduction in oxygen concentration or a reduction in ambient density. Furthermore, fuel effect on soot formation also has been studied showing a big difference between both fuels, diesel is known to be more prone to produce soot than $\mathrm{n}$-Heptane reducing the ability of the technique implemented, especially in conditions with high temperature and high density.
\end{abstract}

Keywords: Diesel, n-Heptane, Soot formation, Multi-hole diesel injector, Optical thickness, Soot cloud, High-speed diffused back illumination

$\begin{array}{llll}\text { Nomenclature } & & \\ \text { ASOE } & \text { After start of energizing } & & \\ \text { DBI } & \text { diffused back-light illumination } & \text { path length } \\ \text { EGR } & \text { exhaust gas re-circulation } & \text { LED } & \text { light-emitting diode } \\ \text { fps } & \text { frames per second } & \text { LEM } & \text { laser extinction method } \\ \text { fv } & \text { soot volume fraction } & \text { LII } & \text { laser-induced incandescence } \\ \text { FWHM } & \text { full width at half maximum } & L O L & \text { lift-off length } \\ I & \text { measured transmitted intensity } & \mathrm{O}_{2} \% & \text { oxygen concentration } \\ I D & \text { Ignition Delay } & \text { PID } & \text { proportional-integral-derivative } \\ I_{F} & \text { intensity of the flame } & p_{\text {inj }} & \text { injection pressure } \\ I_{0} & \text { background intensity } & \text { SOI } & \text { Start of injection } \\ K & \text { dimensional extinction coefficient } & \text { SSI } & \text { Second stage of ignition } \\ k e & \text { dimensionless optical extinction coefficient } & T_{a m b} & \text { ambient temperature } \\ K L & \text { optical thickness from soot } & \rho_{a m b} \text { ambient density }\end{array}$

Cite as:

Payri, R., Gimeno, J., Cardona, S., Ayyapureddi, S. "Experimental study of the influence of the fuel and boundary conditions over the soot formation in multi-hole diesel injectors using high-speed color diffused back-illumination technique." Appl. Therm. Eng. 2019, Vol. 158, 113746, doi:10.1016/J.APPLTHERMALENG.2019.113746.

* Corresponding author. Tel.:+34963879658; fax.: +34963877659

E-mail address: rpayri@mot.upv.es. 


\section{Introduction}

Pollutant emissions (mainly soot) and particular matter (PM) formed in the combustion process of the fuel jets from diesel engines have been a major concern in the last decade [1]; particularly from older diesel vehicles predating Euro 6 standards. As a result, more stringent emissions standards for diesel engines have led to the use of new exhaust after-treatment such as diesel particular filters, which have helped minimize this problem greatly in the last decade. Due to this growing interest to find methodologies for reducing the pollutant emissions, it has been necessary to study the combustion phenomena, mainly around the factors that are related to the formation of these, where the particulate matter is knowns for its detrimental effects on health and the environment [2].

Several methodologies have been developed to understand the combustion process. Ignition delay (ID) and lift-off length $(L O L)$ have been used largely by many researchers [3-7] to comprehend and explain phenomena present in it. Soot formation in diesel fuel jets under different operating conditions is phenomena of quite an interest for the automotive sector, so it has been necessary to develop techniques for its study, within which we can mention laser-induced incandescence (LII) and laser extinction measurement (LEM), which represent the most common techniques employed in-situ optical diagnostic for characterization of soot volume fraction (fv). Pickett and Siebers [8] used LEM to measure the soot optical thickness across a fuel jet and planar laser-induced incandescence (PLII) to visualize the spatial location of the soot in a fuel jet qualitatively and determine the radial widths of the soot region. Payri et al. [9] used the Two-color method that consists in an optical thermometry technique to study the presence of soot within the diesel flame, they evaluated the influence of injection pressure, air density, and ambient gas temperature on the Two-color technique derived parameters.

Line-of-sight attenuation imaging technique have also been used to determinate the soot concentration in diesel fuel jets. Nakakita et al. [10] used the Schlieren and back-illumination methods to study the soot clouds, they confirmed through the evaluations that back illumination was the best method to visualize the soot cloud. Snelling et al. [11] employed a technique for acquiring two-dimensional soot-volume-fraction in laminar flames; they managed to minimize the effect of the beam steering using a precise optical arrangement resulting in maps with a low noise concentration. Yi Xu et al. [12] measured soot volume fraction through forward-illumination light-extinction technique in two-dimensional soot concentration with a single window. Thomson et al. [13] used a technique of the diffuse-light two-dimensional line-of-sight attenuation for study ethylene-air laminar non-premixed co-annular achieving very high levels of the sensitivity in transmissivity measurements through diffused illumination and avoiding the interference due to beam steering.

Currently, there is another new technique to characterize the soot formation and it is known as the high-speed two colors diffused back illumination extinction. Manin et al. [14] employed this technique and simultaneously laser extinction to study the soot formation in n-dodecane sprays, they concluded a preference for shorter visible wavelengths, as soot-generated extinction is higher while broadband flame emission is lower at these wavelengths. Consequently, shorter visible wavelengths resulted in a greater signal-to-noise ratio, Skeen et al. [15] made similar measurements using this technique to evaluate the soot formation in $\mathrm{n}$-dodecane jets under diesel engine relevant conditions finding concordance with results of the previous works. Additionally, Bardi et al. [16] employed this technique in order to understand the formation and oxidation of soot in diesel combustion using a set of fuels with different cetane number and sooting index, performing parametric variations in the test conditions.

This work presents the measurements of lift-off length, ignition delay, and mainly the study of the evolution of soot formation, $\left(M_{S o o t}\right)$, in diesel and n-Heptane fuel jets of two prototypes multi-hole diesel injectors. The study was performed in a high-temperature and high-pressure vessel, performing parametric variations in the boundary conditions (i.e., ambient gas temperature, ambient gas density, injection pressure and oxygen concentration). To determine the soot formation was used the high-speed color diffused back illumination technique. Manin et al. [14] employed a similar technique, but using two light-emitting diode (LED) of different color, for this study was employed an only color; a blue LED with a wavelength of $460 \mathrm{~nm}$ that was utilized to illuminate behind the jets of fuel through the optical access of the novel posterior window. Additionally, the ignition delay and lift-off length phenomena were performed in order to understand the behavior of the soot mass evolution in the formation phase.

The main contribution of the current work has been implementing a new optical arrangement to determine the soot concentration in multi-hole injectors applying a high-speed color diffused back-illumination technique. Diffused back-illumination technique has widely used [16, 14, 17, 9, 8, 18] to determine soot concentrations in single-hole injectors, their results are in good agreement with the trends found in the literature using laser techniques [8, 19, 14]. However, lasers commonly provide only a single image per injection, but no information 
about the temporal evolution of soot during a single injection event and also a high amount of soot causes significant laser attenuation. On the other hand, due to the difficulties to determine soot in real multi-hole injectors for the complexity of the optical arrangement, the studies reported in the literature about these are limited. In this work, it was measured the temporal evolution of soot during the injection event of a real multi-hole diesel injector using a high-speed color diffused back-illumination technique with a new optical arrangement. It is important to mention that a high amount of soot reduces the ability of this technique. In order to understand the soot's behavior, several critical factors were measured such as lift-off length and ignition delay. The results providing a quantitative measurement to aid in the development of predictive models and the trends were found to be consistent throughout the complete test matrix. Results are in good agreement with the trends found in the literature for single-hole diesel injectors.

The present work is formed by four mainly sections. Following the present introduction, the material and methods are explained, including the new optical setup description and the image processing to obtain, $L O L, I D$, and $K L$, the steps and assumptions to calculate the $M_{S o o t}$ is also presented. The third section presents the results of the methods employed to study the combustion phenomena and soot formation with different fuels, injectors, ambient conditions, and various injection pressures. The last section contains the conclusions of this work.

\section{Materials and methods}

This section explains the setup used to carry out this research, as well as an explanation of $I D, L O L$, and $\left(M_{S o o t}\right)$ processing methodology, equations and main parameters selected to determine the soot mass.

\subsection{Hardware}

\subsubsection{Injection system}

The injection system consisting of an air-driven fuel pump and electronic valve to control the pressure in the commercial common rail. This system can generate high rail pressures of up to $3500 \mathrm{MPa}$ and maintain it at the set value while injecting fuel. The energizing time of the injection was $1300 \mu \mathrm{s}$ and it was kept fix for all measurements, and the nozzle tip of the injector was fixed at a constant temperature of $323 \mathrm{~K}$ using an aluminum shield nozzle holder similar to one used by Gimeno et al. [20]; injector holder was designed to have a coolant flowing in direct contact with the injector. The injector's return line was pressurized to $0.8 \mathrm{MPa}$ as required by the injection system to work properly. The rest of the injection system is composed of high-pressure lines and some valves to guarantee uniform pressure.

\subsubsection{Visualization test rig}

A new high pressure and high temperature vessel used for the experiments is presented in Fig 1 This test rig can be operated in steady thermodynamic conditions which are appropriate to compare with diesel engine conditions. It consists of constant pressure and flow test chamber, similar to the one used by Payri et al. [21, 4]. This vessel can reach $1100 \mathrm{~K}$ and $15 \mathrm{MPa}$ of chamber temperature and pressure respectively under different oxygen concentration. Furthermore, it has a bigger optical access (181 $\mathrm{mm}$ of diameter) than the old facility (130 $\mathrm{mm}$ of diameter) which allows a wider field of view for study the injection phenomena. Additionally, heat losses of the test chamber have been reduced with a thicker cross section of insulating material and an improved design of the test section and injector holder. This improves the temperature distribution inside the chamber that can have a considerable effect on the results. Multiple sensor input connection ports are available and located in different angles and heights of the outer wall of the vessel, allowing for different sensors to enter the test chamber (e.g. thermocouples, pressure sensor). 


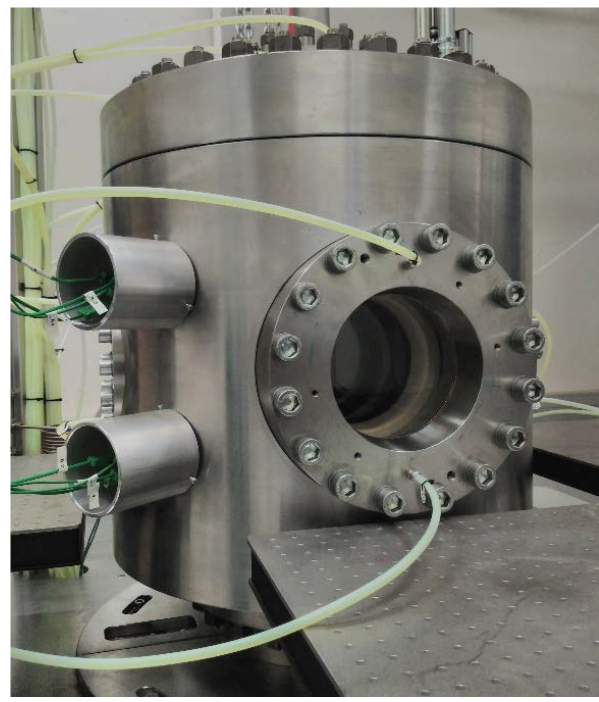

Fig. 1: Lateral view of the high-pressure and high-temperature visualization vessel.

The new facility is formed by four main sub-sections: high-pressure system, heaters, test vessel, and control system. Air is compressed and stored in high-pressure reservoirs. After passing through an industrial dryer to remove humidity from the air, it enters to the test chamber through a $30 \mathrm{~kW}$ electric heating system, controlled by a PID with a temperature set-point, fixed at the desired level. Another PID system controls the chamber pressure with a flow control valve that feeds high-pressure air. Also, the facility is capable of being operated in an open or closed circuit to test spray development either in a standard air atmosphere or with gas/ $N_{2}$ mixtures with different $\mathrm{O}_{2}$ concentration, enabling to simulate the re-circulation of exhaust gas (EGR) by decreasing the oxygen content of the charge. It is even possible to operate the test rig in non-reacting conditions with $100 \%$ $\mathrm{N}_{2}$. The chemical composition of the gas in the chamber is permanently measured by a lambda sensor and can be adjusted adding either air or nitrogen through a regulation system. Hot gases exit the vessel and, after being cooled down, are thrown into the atmosphere.

Special injector holder has been used to keep the injector working a constant temperature along the experiments through a circuit of ethylene glycol; the nozzle tip temperature is fixed to keep it constant in each test condition due influence on the sprays [22]. Fig. 2 shows a schematic diagram of the new facility.

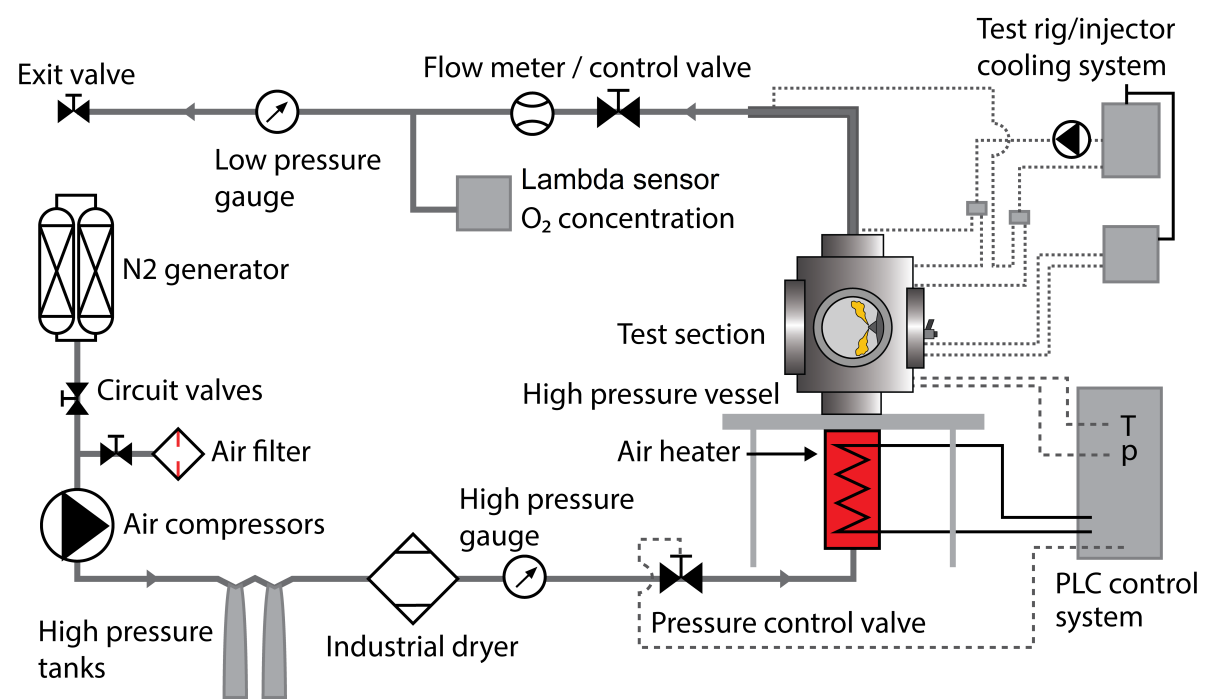

Fig. 2: Global diagram of the high pressure and temperature facility. 


\subsubsection{Posterior window}

A novel posterior window has been used in order to determine the soot concentration in multi-hole diesel injectors, which can be seen in Fig. 3 The new window includes a special injector holder connected to a refrigeration system, it ensures a constant temperature of the nozzle tip throughout the experiments, minimizing the variation of the fuel jet properties. Also, it has optical access which is composed of a high-temperature window and high-pressure window behind the sprays, enabling the LED's illumination can go through the soot cloud in the combustion process and allowing to determine the soot concentration. Additionally, between the hoop and the injector holder, there is a cross-section of insulating material to avoid the heat losses of the test chamber.

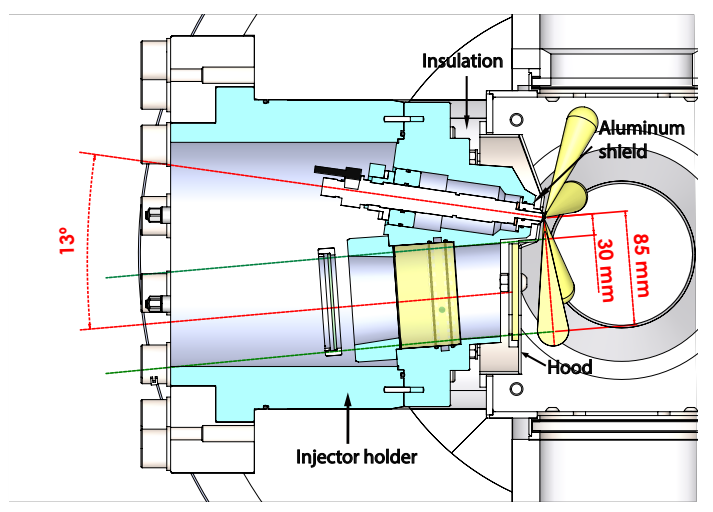

Fig. 3: Section wiew of posterior window.

This novel window allows visualizing the spray jet between 30 to $85 \mathrm{~mm}$, considering the complexity of the assembly and the quite confined space, it is a long view length, which is very important in order to observe as much as possible evolution of the soot formation, which takes place downstream from the injector tip and it varies with the boundary conditions. The injector holder has an inclination in accordance with spray angle with the goal that the spray's axis and optical window be parallel with each other. A new injector clamp allows the injector rotation to locate the selected fuel jet in the horizontal position facilitating the processing of images and ensuring that the jet of interest is the same throughout tested conditions.

\subsubsection{Test matrix}

The test plan, presented Table 1 is centered on the boundary conditions performed for this study, it shows the ranges of the ambient density, ambient temperature, and oxygen concentration that were used for this campaign. Also, the injection pressure was variated from 100 to $250 \mathrm{MPa}$. Skeen et al [15] studied soot volume fraction in n-Dodecane flames, variating the operating conditions (i.e., ambient temperature, density, and oxygen concentration), they observed that the largest amount of the total soot mass was formed under conditions of high-density, high-temperature, and low oxygen concentration. Additionally, all experiments were performed for two prototype injectors denoted as "PMI20" and "PMI25" with maximum injection pressures of $200 \mathrm{MPa}$ and $250 \mathrm{MPa}$ respectively. Fuels selected to perform all experiments were two different fuels, high-quality commercial fuel (Diesel) and n-Heptane.

Table 1: Test matrix.

\begin{tabular}{lll}
\hline Parameter & Values & Units \\
\hline Injectors & "PMI20" and "PMI25” & - \\
Energizing time & 1.3 & $\mathrm{~ms}$ \\
Injection pressure $\left(p_{\text {inj }}\right)$ & $100-150-200-250^{a}$ & $\mathrm{MPa}$ \\
Oxygen perc. $\left(O_{2} \%\right)$ & $13-17-20.9$ & $\%($ vol. $)$ \\
Tip temperature $\left(T_{\text {tip }}\right)$ & 323 & $\mathrm{~K}$ \\
Gas temperature $\left(T_{\text {gas }}\right)$ & $800-900-1000$ & $\mathrm{~K}$ \\
Gas density $\left(\rho_{\text {gas }}\right)$ & $10-18-28$ & $\mathrm{~kg} / \mathrm{m}^{3}$ \\
\hline${ }^{a}$ Only injector "PMI25" & & \\
\hline
\end{tabular}

Fuel properties relevant to this study are referred to in Table 2 n-Heptane properties were extracted from the date base of engine combustion network $(\mathrm{ECN})$ and Diesel properties were obtained of the datasheet of the 
distributor company. For the current work, the fuel temperature was set at $300 \mathrm{~K}$ and kept it constant throughout the complete test matrix, to avoid temperature effect on lift-off length, ignition delay, and soot formation, [6, 20] reported some of this effects. The temperature was set at this value in order to compare with the computational models and avoid changes in fuel properties.

Table 2: Fuel properties.

\begin{tabular}{llll}
\hline Fuel property & n-Heptane & Diesel & Units \\
\hline$\rho_{f}^{a}$ & 678 & 832 & $\mathrm{~kg} / \mathrm{m}^{3}$ \\
Kinematic viscosity ${ }^{a}$ & 0.56 & 3.1 & $\mathrm{~mm}^{2} / \mathrm{s}$ \\
Cetane number & 56 & $55^{b}$ & - \\
Lower Heating Value & 44.6 & 44.5 & $\mathrm{MJ} / \mathrm{kg}$ \\
\hline${ }^{a}$ Density and kinematic viscosity at the fuel temperature of $300 \mathrm{~K}$, and atmospheric pressure of $0.1 \mathrm{MPa}$ & \\
${ }^{b}$ Minimum value guaranteed by distributor company & \\
\hline
\end{tabular}

\subsection{Experimental techniques and setups}

\subsubsection{Natural luminosity visualization}

The light emitted due to the chemical reactions during the combustion process (chemiluminescence) has been used in this work to determine the ignition delay, that is generally known as the elapsed time between the start of the injection and the first exothermic reactions [23, 24]. The light can be seen and recorded as a signal through time, Pickett et al. [25] highlighted the close relationship between chemiluminescence and ignition delay. The optical setup used for study this parameter consists mainly of a high-speed camera (Photron SA5) equipped with a $100 \mathrm{~mm}$ Zeiss lens and a low pass filter of $390 \mathrm{~nm}$ to reduce the luminosity produced from the combustion and thus, avoid the pixel saturation. Optical components were located in front of the fuel jets, observing the broadband chemiluminescence produced during the combustion through the frontal window of the vessel. Ignition characterization has been focused only on a jet in order to improve the temporal resolution with the increase of the number of samples per second as a result of the reduction of view area and in this way determine the ignition delay with good accuracy. Detail of the optical setup used is presented in Table 3

\subsection{2. $\mathrm{OH}^{*}$ chemiluminescence}

Recorded of chemiluminescence from chemicals reactions, mainly by the $\mathrm{OH}^{*}$ in the combustion process is a technique widely employed in combustion investigation [3, 4, 26]. This technique has been used to characterize the Lift-off length that is defined as the length between injector tip and the zone where the combustion reactions stabilize, Pickett et al [27] defined the lift-off length $(L O L)$ as an indicator of the time that air and fuel mixing takes before ignite. Additionally, Peters [28] defined lift-off length as the length from the nozzle tip to the zone where the jet velocity and flame front speed stabilize at determined conditions. Higgins and Sieber [7], who first measured LOL using an intensified camera fitted with an interferometric filter, concluding that $\mathrm{OH}^{*}$ was a good indicator to measure the lift-off length. An ICCD Andor iStar camera fitted with a $100 \mathrm{~mm} \mathrm{f} / 2.8 \mathrm{UV}$ lens and a $310 \pm 5 \mathrm{~nm}$ CWL filter were used to record the $\mathrm{OH}^{*}$ chemiluminescence. A constant intensifier gating time between 1.8 and $4.6 \mathrm{~mm}$ was used in order to capture an average image of the injection time and reduce the deviation between repetitions. Table 3 summarized the detail from the optical setups.

Table 3: Details of the optical setup for the employed techniques.

\begin{tabular}{llll}
\hline & $\begin{array}{l}\text { Diffused back- } \\
\text { illumination }\end{array}$ & $\begin{array}{l}\text { Natural } \\
\text { luminosity }\end{array}$ & $\begin{array}{l}\text { OH }^{*} \\
\text { chemiluminescence }\end{array}$ \\
\hline Camera & Photron SA5 & Photron SA5 & Andor-iStar \\
LED pulse duration & $1 \mu \mathrm{s}$ & - & - \\
Filter CWL & $460 \mathrm{~nm}$ & $390 \mathrm{~nm}$ & $310 \mathrm{~nm}$ \\
Frame rate & $50 \mathrm{kfps}$ & $50 \mathrm{kfps}$ & 1 frame per inj. \\
Resolution & $512 \times 272$ & $512 \times 272$ & $1024 \times 1024$ \\
Shutter time & $2.1 \mu \mathrm{s}$ & $20 \mu \mathrm{s}$ & - \\
Pixels/mm ratio & 5 & 5.1 & 8 \\
Repetitions & 20 & 10 & 10 \\
\hline
\end{tabular}




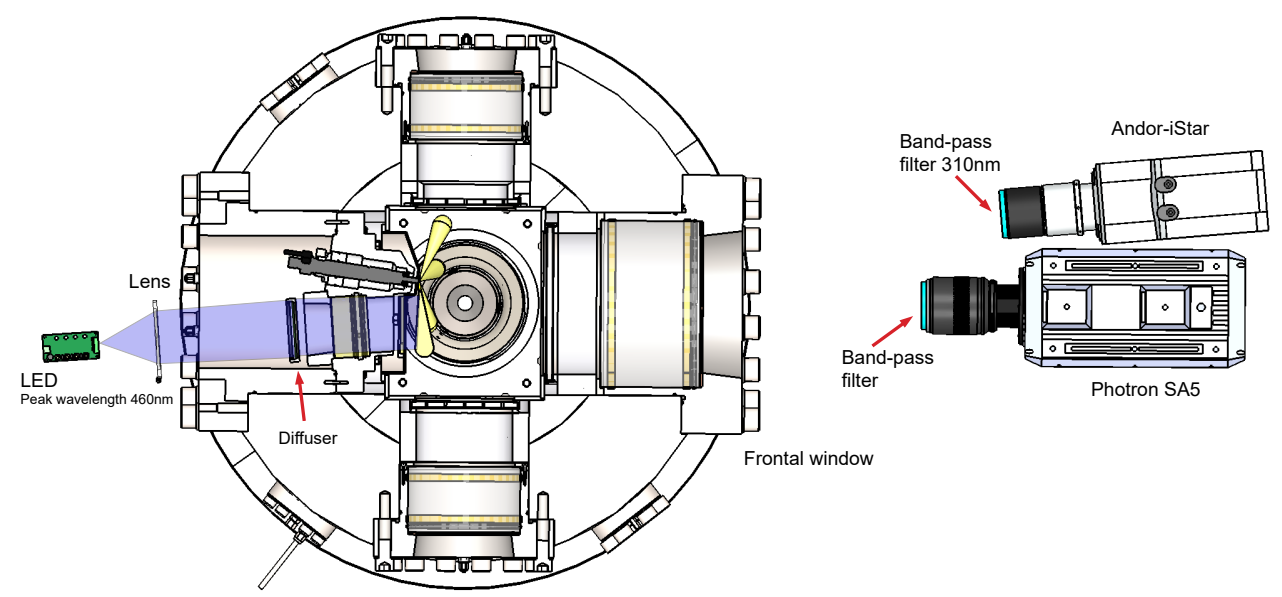

Fig. 4: Optical setup used for: high speed color back-illumination, Natural luminosity and $\mathrm{OH}^{*}$ chemiluminescence

The principle of this technique is based in the one used for study spray liquid phase penetration and consists of the consideration of the liquid phase as the dark silhouette of the spray when the background is illumined with a diffuse beam light. High-speed color diffused back illumination diagnostic setup employed in this study is composed mainly of a LED light source and a high-speed camera (Photron SA5) on opposing sides of the fuel jet in a line-of-sight arrangement. A blue LED with a wavelength of $460 \mathrm{~nm}$ was selected for this study. Manin et al. [14], studied back-illumination with two wavelengths $519 \mathrm{~nm}$ (green LED) and $406 \mathrm{~nm}$ (blue LED) they observed that shorter wavelengths are appropriate to measure soot concentration, this corresponds to the blue LED. The one selected can produce short and high-power pulses of light, and high rate of repetitions. A LED pulse duration of $1 \mu \mathrm{s}$ was selected as a compromise between intensity illumination and camera speed. LED's illumination pass through a Fresnel lens to collect this illumination and focus it over the engineered diffuser which has a divergence angle of $20^{\circ}$ and $100 \mathrm{~mm}$ of the diameter, the diffuser in conjunction with the Fresnel lens create a uniform background intensity to illuminate the spray, this optical setup is similar to the one used by Payri et al. [29, 30] to study liquid phase penetration.

A high-speed camera (Photron SA5) was located on the other side of the sprays and was set with a speed of 50.000 frames per second (fps). For this study the camera was equipped with a $100 \mathrm{~mm}$ Zeiss lens and a narrow band-pass filter that transmits from $455 \mathrm{~nm}$ to $465 \mathrm{~nm}$ (measured at FWHM). This filter was placed in front of the camera objective and thus, prevents the illumination from the flame come through the camera and only lets the spectrum of the blue LED to pass through it. The exposure time of the camera was set to $2.1 \mu \mathrm{s}$ with the goal of capture the highest intensity period of the LED illumination and to minimize the natural luminosity from the flame that is captured. A detailed top view of the optical setup for the high-speed color diffused back illumination technique is presented in Fig. 4

\subsection{Image processing}

The image processing is one the most important process of any visualization data study. Images were processed using a home-built software developed with the purpose of calculating the parameters following the method explained below:

\subsubsection{Ignition delay}

Methodology employed to determine the ignition delay $(I D)$ is as follows, the maximum intensity of all pixels of the imagines captured through the natural luminosity technique was measured for each frame. This intensity was normalized, and background level was considered by evaluating a range of frame before the injection. A threshold of $5 \%$ over the background level was fixed to binarize the images, interpolating the time of the first 
image that exceeds that threshold and the previous frame. That was made for all repetitions and the final result is the average between them. Ignition delay reported in this work is respect to the start of injection (SOI).
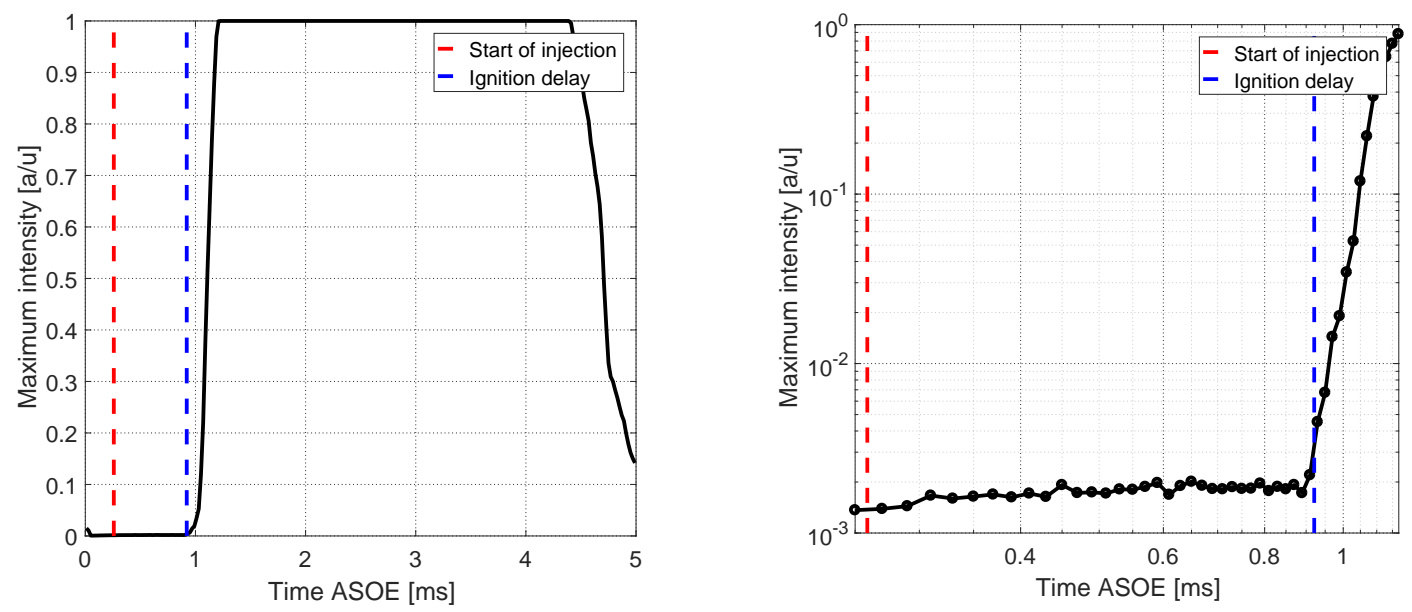

Fig. 5: Example of the natural luminosity processing and the calculation of the ignition delay. Left: Intensity profile vs. time. Right: Same as Left but zoomed and a logarithmic scale near to the ignition start $\left(T_{\text {gas }}=900 \mathrm{~K}, \rho_{\text {gas }}=18 \mathrm{~kg} / \mathrm{m}^{3}\right.$, oxygen concentration $=21 \%$, diesel, $p_{i n j}=$ $100 \mathrm{MPa}$, and injector $=\mathrm{PMI} 20$ ).

This method, despite not describing necessarily the beginning of the high-temperature reactions known as second stage of ignition (SSI), detects robustly precursor reactions of the combustion thanks to the high sensitivity of recording and the short temporal gap between frames. This first indication of chemical reactions occurrence is also associated with the test conditions and how they affect combustion quality and make the spray more prone to ignition, being a suitable measure to make a direct analysis of the effect of the boundary conditions on the combustion process.

\subsubsection{Lift-off length}

The proposed methodology divides the flame from each orifice into a top and bottom profiles to account differences in flame shape. A fixed threshold of 0.6 between the $5 \%$ and $95 \%$ intensity levels of the image was set for all conditions tested, this value is multiplied by the noise level. For each profile, lift-off length is defined as the distance between the nozzle tip and the closest point in the flame where its width is bigger than a predefined minimum width value (named $\mathrm{K}$ measured in pixels) over the threshold. $\mathrm{K}$ is an arbitrary value for tuning, in this case, 5 pixels. Finally, lift-off length is defined as the global average between top and bottom profiles lift-offs, for each spray and every repetition.
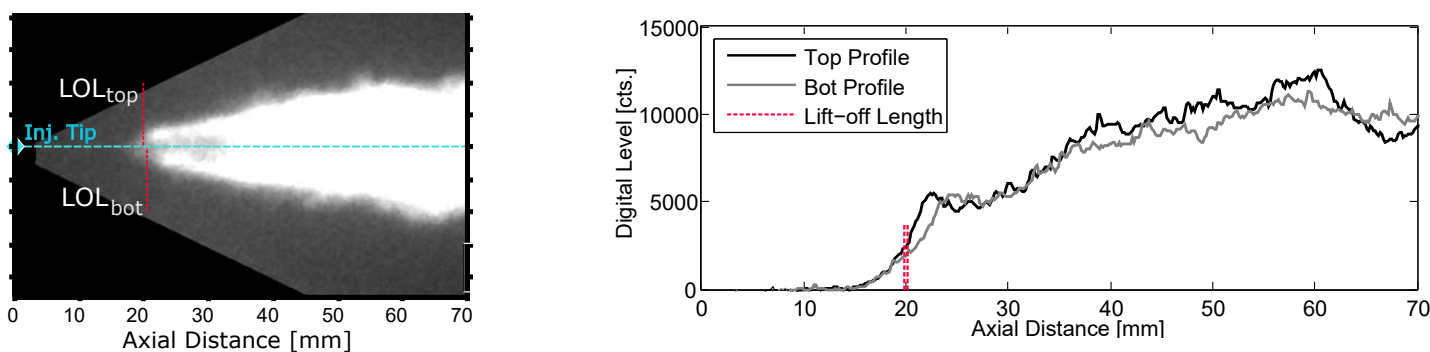

Fig. 6: Test sample of the $\mathrm{OH}^{*}$ imaging and $L O L$ intensity profile. Left: sample image from the ICCD Andor iStar, dashed blue line represents the LOL with a $60 \%$ thresold results. Right: intensity profiles for both top (black) and bottom (gray) portions of the flame, dashed red lines correspond to LOL measured with a $60 \%$ of the intensity peak. $\left(T_{\text {gas }}=900 \mathrm{~K}, \rho_{\text {gas }}=18 \mathrm{~kg} / \mathrm{m}^{3}\right.$, oxygen concentration $=17 \%, p_{i n j}=200 \mathrm{MPa}$, diesel, and injector $=$ PMI20).

\subsubsection{Soot formation}

Diffused back illumination procedure consists of a successive camera captures where frames with the LEDon and LED-off are interspersed. The level of intensity in the frames recorded with the LED-on is the product of the illumination from the LED and the combustion flame, while in the frames recorded with the LED-off, 
the illumination is just product of the natural luminosity from the flame thus, the intensity level recorded only depends on the test point conditions. The camera is responsible for sending the trigger that turns on the LED, doing this at half the acquisition frequency of the camera and in consequence acquiring one frame with the LED-on and the subsequent one with the LED-off.

Optical thickness, $K L$, calculation was based in Beer-Lambert law with a modification as follows.

$$
\frac{I-I_{F}}{I_{0}}=e^{-K L}
$$

Where $I$ is the measurement of the attenuation of the intensity due to the soot cloud, it is the total intensity from the LED-on and flame. $I_{F}$ is the intensity of the flame with LED-off. Due to the impossibility of measuring I and $I_{F}$ at the same time, a motion interpolation algorithm was employed to process the frames and generate the extra frame between each pair of frames for both conditions (LED-on and LED-off).

The motion interpolation is used to process the images in an attempt to make the animation more fluid and guarantee that $I-I_{F}$ is the result of subtracting the two frames at the same time step, a better explanation of this procedure is detailed in [31].

$I_{0}$ is the background intensity measured with LED-on and without spray, $K$ is the dimensional extinction coefficient, and $L$ is the length of the path through the soot cloud. For optical thickness values larger than 4 , the back-illumination technique can't determine with accuracy the soot concentration due to the high extinction by the amount of soot in conditions that promote a high formation.

$K L$ has been calculated by averaging 20 injection events, this average help to avoid negative pixels when subtracting and diminishing beam-steering effects caused by fluctuating density gradients inside the chamber. A graphic explanation of how the $K L$ was obtained is presented in Fig. 7 the optical thickness is proportional to the mass of soot along the line of sight of the extinction measurement.

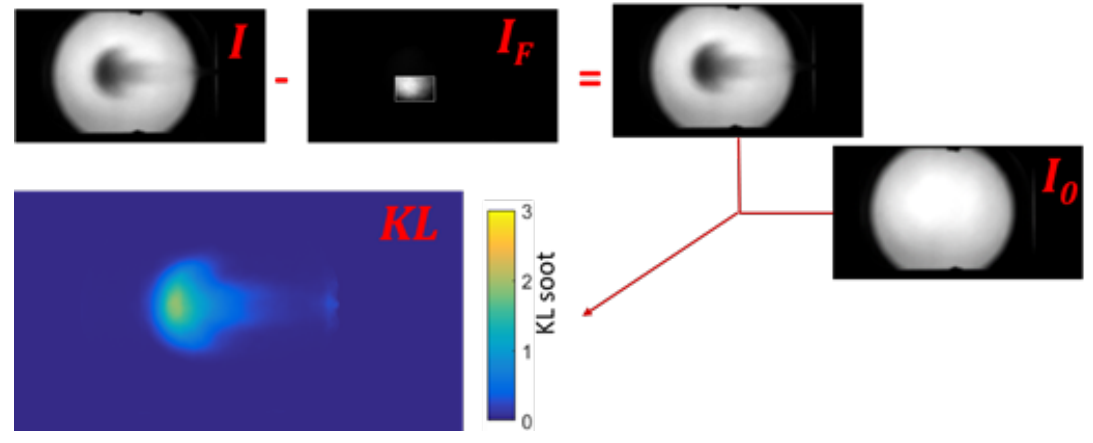

Fig. 7: Graphic explanation of the methodology implemented to determine the optical thickness $(K L)$.

This technique has limitations, one of them is the image lag effect that is associated with the camera performance; when the gradients in illumination intensity occur between successive images, one particular image intensity distribution may affect the following images. Manin et al. [32] studied this effect and highlighted the complexity of the process and difficulty to quantify the effects of image lag, also this study revealed that the image intensity could be affected by a small percentage.

The procedure necessary to obtain the soot volume fraction and the soot mass as measured by extinction has been done following the steps used by Manin et al. in [14] and the parameters employed to calculated the optical soot properties through Rayleigh-Debye-Gans (RDG) are similar and they are grouped in the table 4

$K L$ has been determined from high-speed color diffused back illumination technique for each test condition, additionally, from equation 2 can be inferred how is related soot volume fraction, $f_{v}$, with $K$. The soot volume fraction could be calculated of measurement of KL extinction using the following relationship derived from small particle Mie theory [8].

$$
f_{v}=\frac{K \lambda}{K_{e}}
$$

where $\lambda$ is the LED wavelength and $k_{e}$ is the dimensionless optical extinction coefficient. The dimensional extinction coefficient can be obtained following the procedure reported by Pickett [8], which was obtained from 
Table 4: Parameters used for the calculations of soot properties.

\begin{tabular}{ll}
\hline Parameters & Values \\
\hline Fractal factor $K_{f}$ & 8.36 \\
Fractal Dimension $D_{f}$ & 1.77 \\
Refractive index $m$ & $1.75-1.03 \mathrm{i}$ \\
Extinction coefficient $k_{e}$ & 7.59 \\
Aggregate size $N_{p}$ & 150 \\
Particle diameter $d_{p}[\mathrm{~nm}]$ & $16 \mathrm{~nm}$ \\
Collection angle $[\mathrm{mrad}]$ & $162 \mathrm{mrad}$ \\
Wavelength $\lambda[\mathrm{nm}]$ & 460 \\
\hline
\end{tabular}

the Rayleigh-Debye-Gans theory. Additionally, they described widely $k_{e}$, and the values used in soot studies. For this study, a value of $k_{e}=7.59$ was calculated according to equation 3 where $\alpha_{s a}$ is the scattering-to- absorption ratio and $\mathrm{m}$ is the refractive index of soot, this value presents good agreement with other works [14 33] 18]. The details of the RDG theory and all the parameters used for calculating the $k_{e}$ are referenced from [14, 34].

$$
k_{e}=\left(1+\alpha_{s a}\right) \cdot 6 \pi \cdot E(m)
$$

The soot volume fraction can be calculated using equation 2 but it is necessary to know the values of $\mathrm{K}$ and $\mathrm{L}$ by separately, becoming a complex calculus. However, the soot projected density can be calculated integrating the soot volume fraction along each line-of-sight and following equation 4

$$
M_{\text {soot }}=\frac{\rho K L \lambda}{K_{e}} \quad\left[\frac{\mu \mathrm{g}}{\mathrm{mm}^{2}}\right]
$$

Mass of soot was calculated with an assumed density of $1.8 \mathrm{~g} / \mathrm{cm}^{3}$ for soot, this value was determined by Choi et al [35], studying the collected soot from an acetylene/air premix fame and using a helium pycnometry to determine the value of the density. Same density value has been used in similar studies with diesel injectors and similar optical vessels [36, 15].

\section{Results and discussion}

This section is formed by three subsections which present all results obtained for $I D, L O L$, and soot formation. In Addition, a discussion of the effect of the boundary conditions on the parameters studied through optical techniques employed.

\subsection{ID Results}

Ignition delay is substantially affected by both chemical and mixing processes which is consistent with the results shown in Fig. 8, Fig 9, and Fig. 10 The results found here are in agreement with results found in other studies [3 4 4 6 6], and trends follow the behavior expected. An increase in ambient temperature, oxygen concentration or ambient density leads to an acceleration of the reactions of oxidation, causing an $I D$ shortening. An ignition delay reduction is also sensitive to occur with injection pressure increments, which promotes turbulence, intensifying break-up and air-fuel mixing and facilitating combustion occurrence.

Fig. 8 according with the previous statement, shows a reduction of $I D$ with the increase of the oxygen concentration and ambient temperature for both injectors and both fuels operating at $18 \mathrm{~kg} / \mathrm{m}^{3}$ of ambient density and $100 \mathrm{MPa}$ of injection pressure. Fig. 8 evidence the fuel influence on $I D$, the differences are more visible at the lowest temperature as can be observed in Fig. 9 Ignition delay is higher for n-Heptane than Diesel, this behavior also has been observed by [37, 17, 6] when they used similar fuels to carry out their experiments. When comparing fuels in this study, Ignition delay results lead to think that the chemical kinetics is the dominant factor to the final outcome of the ID delay behavior [38], which could suggest that Diesel has a cetane number higher than $\mathrm{n}$-Heptane. This trend between fuel regarding intensity signals was consistent along the full test matrix. In order to distinguish easily the fuel's trends through sections 3.1 and $3.2 \mathrm{n}$-Heptane has been represented with a dashed light blue line and Diesel with a continuous dark blue line. 

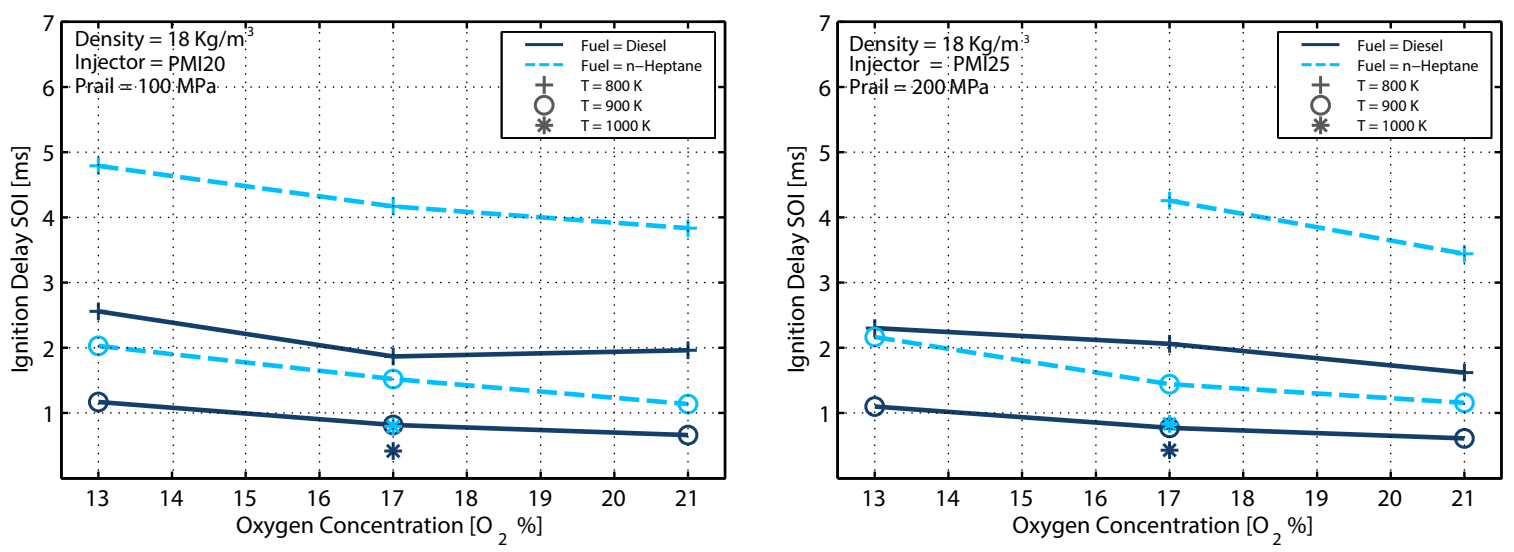

Fig. 8: Ignition delay (SOI) being affected by oxygen concentration and ambient temperature at certain fixed conditions (ambient density $=18 \mathrm{~kg} / \mathrm{m}^{3}$, and $p_{i n j}=100 \mathrm{MPa}$ ). Left: Ignition delay for injector PMI20. Right: Ignition delay for injector PMI25. Continuous dark blue lines represent Diesel fuel trends while a dashed light blue line is for n-Heptane fuel.

Fig. 9 presents the effect on ID of the ambient temperature and ambient density, where the gas temperature showed a larger effect than ambient density, it is easily appreciable for lower temperatures. The slopes are steeper between 800 and $900 \mathrm{~K}$ than between 900 and $1000 \mathrm{~K}$. At these relatively low ambient temperatures, chain-branching reactions are highly dependent on fuel reactivity and oxygen availability for the formation of radicals [39]. These figures also show that the different fuels respond consistently, in terms of ignition performance, to variations in ambient conditions, as is the case for the nozzle. On the other hand, Lower ID at higher temperatures are due less hot air needs to be entrained downstream of the liquid length to start the ignition [40, 6, 41]. Nevertheless, the effect of different nozzles in ignition delay is difficult to see clearly in Fig. 8 and Fig. 9 In both plots appear that both injectors have the same behavior and the values found are similar, mainly at $1000 \mathrm{~K}$ where the nozzle geometry, fuel, and ambient density seems to have an insignificant effect. Differences between the two injectors could be caused by the difference in the hole diameter of the nozzle, in this case, the diameter is bigger at $33 \mu$ s approximately for the injector 'PMI25' than 'PMI20'. Smaller diameters promote better atomization and liquid breakup, due to the thinner liquid core and high fuel outlet velocity [38 42].
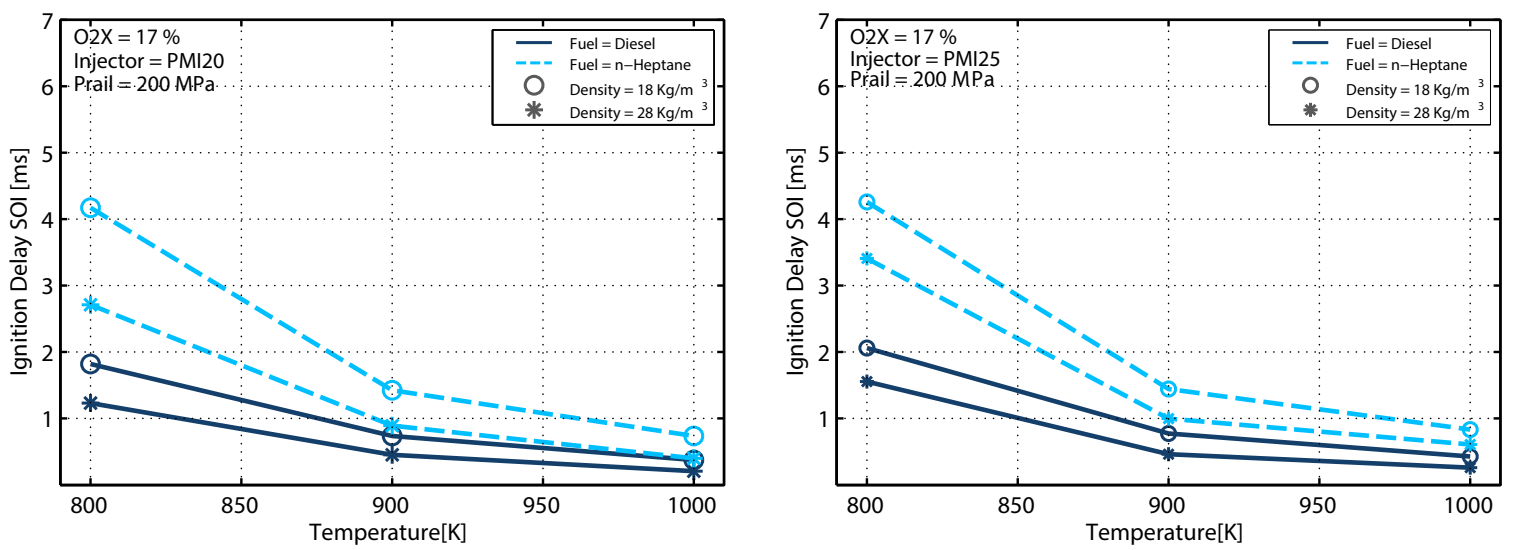

Fig. 9: Ignition delay (SOI) variation with ambient temperature for different ambient density at certain fixed conditions (oxygen contration $=17 \%$, and $p_{i n j}=200 \mathrm{MPa}$ ). Left: Injector PMI20. Right: Injector PMI25.

Finally, the effect of the injection pressure on ignition delay can be appreciated clearly in Fig. 10. where is notorious the imperceptible effect at an ambient temperature of $900 \mathrm{~K}$ and oxygen concentration of $17 \%$, IDs decrease slightly with increasing injection pressure, which is the result of faster liquid break-up and mixture preparation. Also, this behavior agrees with previous works whose studied $I D$ at different injection pressures [3, 4]. 

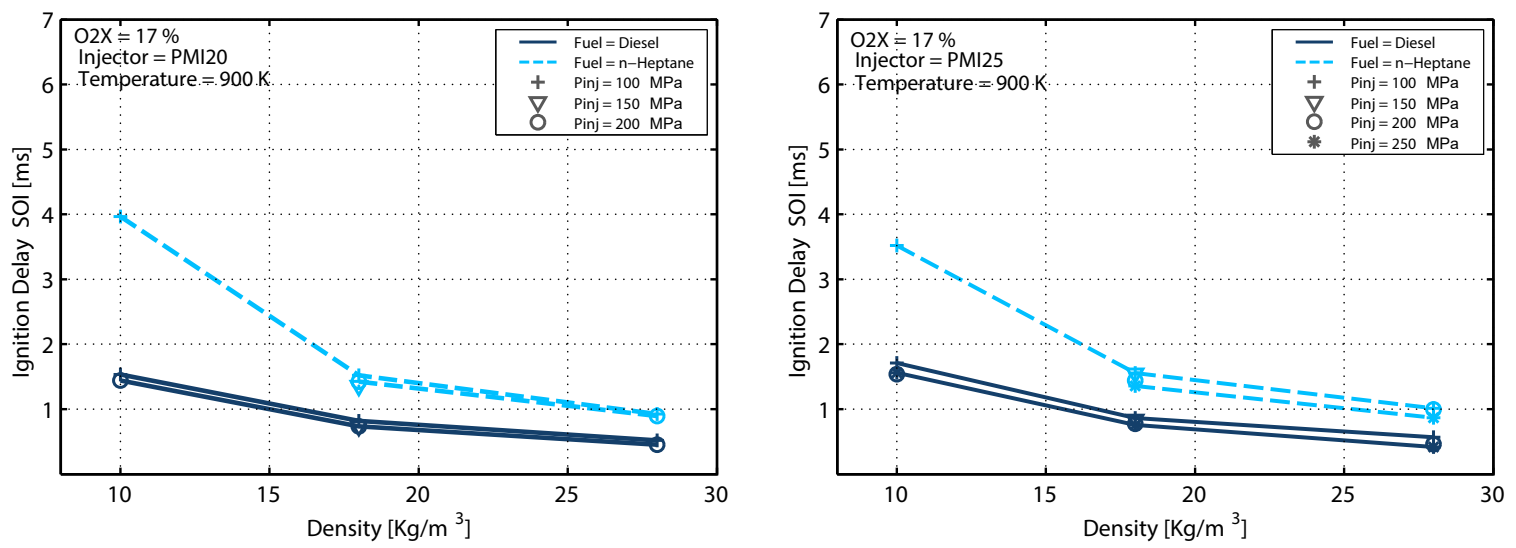

Fig. 10: Ignition delay (SOI) variation with injection pressure and ambient density at certain fixed conditions (oxygen concentration $=17 \%$, and ambient temperature $900 \mathrm{~K}$ ). Left: Injector PMI20. Right: Injector PMI25.

\subsection{LOL Results}

Following the methodology described in section 2.3.2, lift-off length was calculated for a large window of test conditions and parametric variations. Fig. 11 Fig. 12 and Fig. 13 present stabilized LOLs for both fuels and both injectors in a subset of the whole dataset, a sweep of oxygen concentration, ambient temperature, and ambient density at high, intermediate, and low pressures. Results follow the trends expected, and they are consistent with results reported in literature [3-5, 7]. In Fig. 11 is possible to observe the effect of oxygen concentration and ambient temperature on lift-off length for both injectors at the same operating conditions, $18 \mathrm{~kg} / \mathrm{m}^{3}$ of ambient density and $200 \mathrm{MPa}$ of injection pressure. Influence of oxygen concentration on LOL is clearly noted and how it is reduced with increases of oxygen concentration, because of the effect of oxygen concentration in laminar flame velocities, following the concept proposed by Peters in [28]. Alike, the increase of the ambient temperature causes a reduction on $L O L$, this happens as a result of variation of the oxidation process; changing the velocity of the reactions [41].
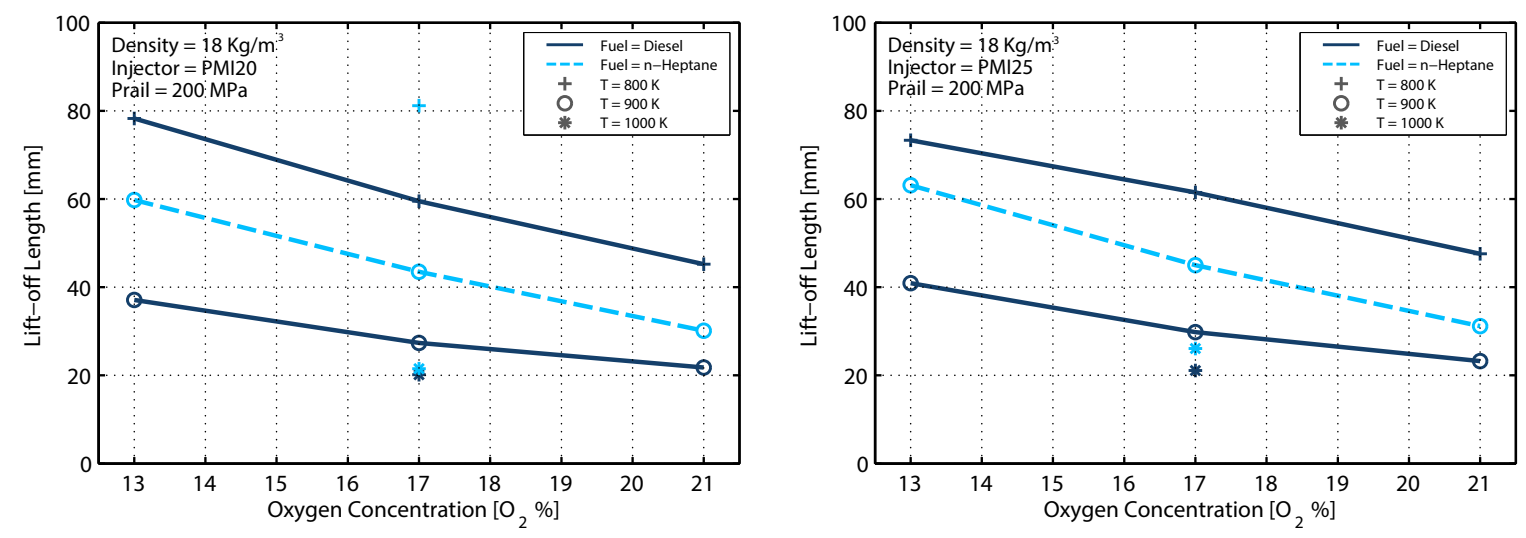

Fig. 11: Lift-off length variation with oxygen concentration for different ambient temperatures at certain fixed conditions (ambient density $=18 \mathrm{~kg} / \mathrm{m}^{3}$, and $\left.p_{i n j}=200 \mathrm{MPa}\right)$. Left: Injector PMI20. Right: Injector PMI25. Continuous dark blue lines represent Diesel fuel trends while a dashed light blue line is for n-Heptane fuel

In Fig. 12 is easily noticeable how the ambient temperature and ambient density affect the lift-off length. Several researchers [3, 6, 43, 7] support the influence of this two parameters on lift-off length, increases of the gas density in the chamber enhance the evaporation and mixing process causing a reduction in lift-off length. Also, higher density implies that more oxygen is available to oxidize the fuel and thus, shorter ignition delays are expected, which reduce the corresponding LOL [7]. At low temperatures is appreciated a more variation than at high temperatures where the LOLs were more uniform and showed less deviation through each repetition as a result of velocities of reaction by high temperatures. 

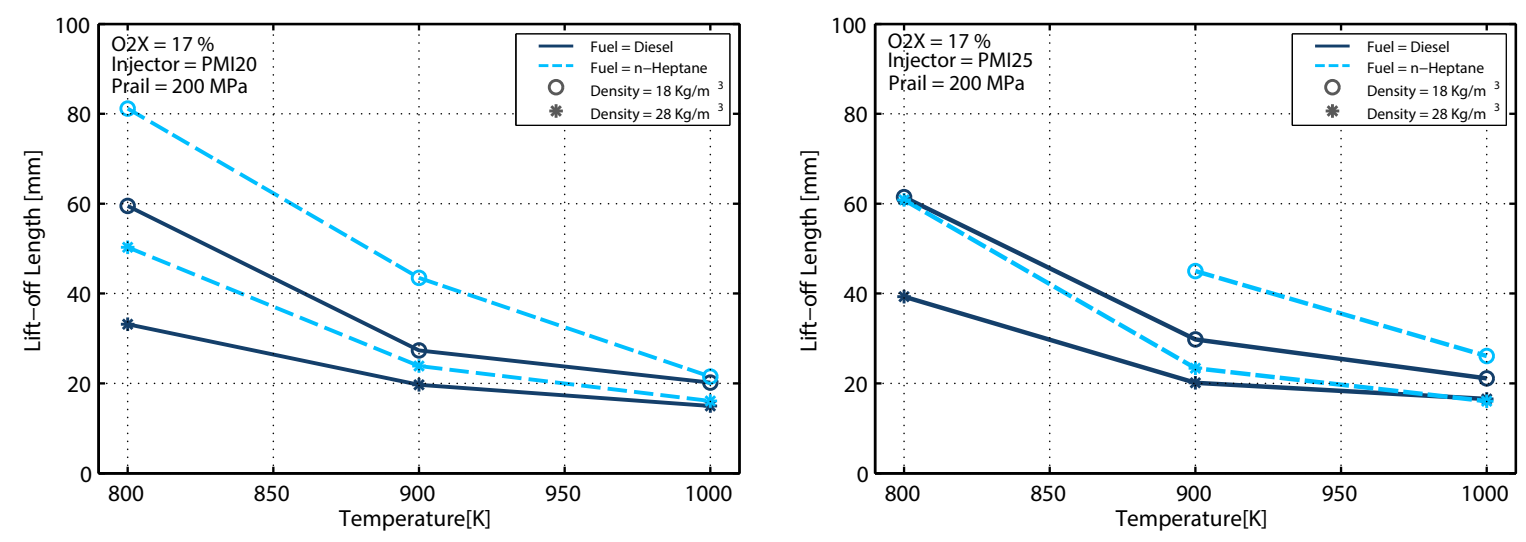

Fig. 12: Lift-off length variation with ambient temperature for different ambient densities at certain fixed conditions (oxygen concentration $=17 \%$, and $p_{i n j}=200 \mathrm{MPa}$ ). Left: Injector PMI20. Right: Injector PMI25.

Fig. 13 presents the effects of the injection pressure on lift-off length, contrary to the effect on the ignition delay, lift-off length increases with higher injection pressures, it can be due to an increase in spray velocity, as liftoff is the region where the stabilization between jet velocity and flame front speed occurs. For larger injections pressures thus, larger injection velocities [44], fuel travels a longer distance for that given ignition delay time. In Fig. 13 is possible to observe how the $L O L$ is more susceptibility at low temperatures and some $L O L$ measured points were quite larger being outside of the view area. Additionally, the difference between two injectors is caused by the difference in the orifice diameters, it was reported in previous studies where was demonstrated that the $L O L$ is slightly affected by orifice diameter, reporting a high $L O L$ with a larger orifice diameter [6, 3].
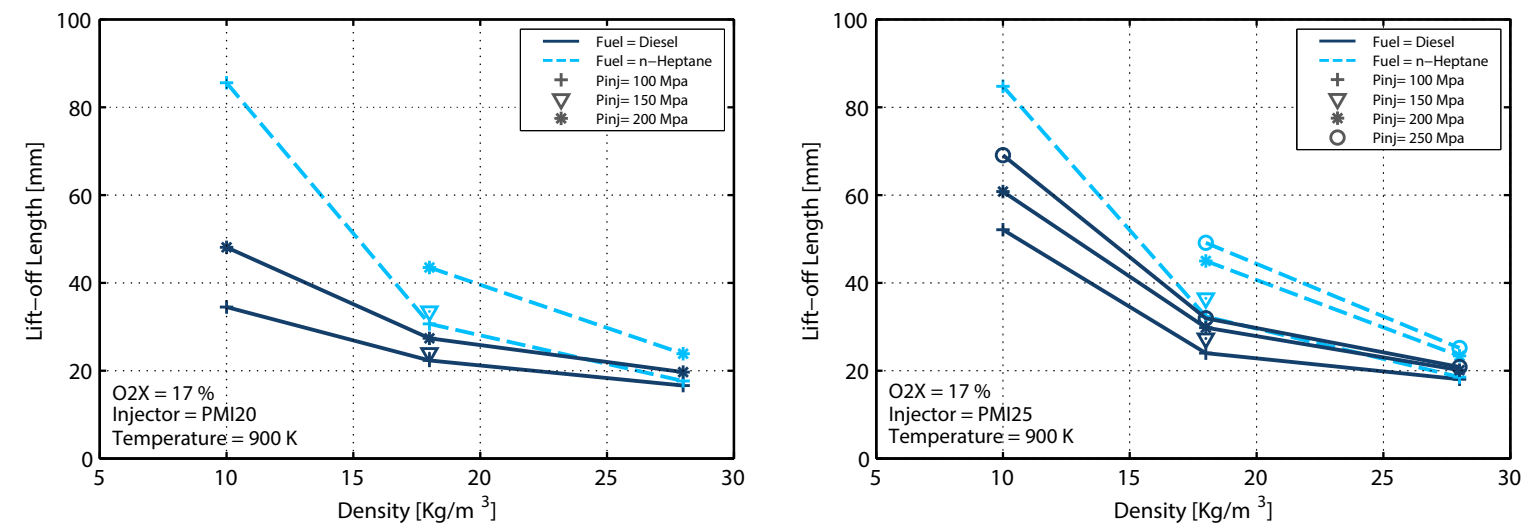

Fig. 13: Lift-off length variation with ambient density for different injection pressures at certain fixed conditions (oxygen concentration $=17 \%$, and ambient temperature $=900 \mathrm{~K})$. Left: Injector PMI20. Right: Injector PMI25.

Finally, it is easily appreciable how the fuel type affects the LOL. n-Heptane consistently showed the longest $L O L s$, followed by the Diesel fuel. Lift-off length is mainly influenced by the ignition delay time, rather than flame velocity [6], the observations in this study agree with that conclusion: regarding fuel properties, $L O L$ is principally determined by the reactivity of the fuel.

As a brief of the sections 3.1 and 3.2 Two fuels with different characteristics were used to investigate ignition processes and lift-off length. The figures are for a range of ambient temperatures, oxygen concentration, and densities. All experimental conditions, including fuel pressure and temperature, were kept constant as the fuel and nozzle type were varied. Comparison of the trends for measured lift-off lengths and ignition delays presents that there does appear to be a general relationship between fuel ignition quality and lift-off length. At all experimental conditions, a fuel with the shortest ignition delay also has the shortest lift-off length. Furthermore, the ignition delay follows the expected trend with respect to the fuel cetane number and to the ambient density. ID decreases with increasing cetane number and with increasing ambient gas density. 


\section{3. $M_{\text {Soot }}$ Results}

The current section is formed by seven subsections which show the influence of the test conditions on soot formation as a result of using the high-speed diffused back-illumination technique during the experiments and employing Eq. 1 Eq. 2 Eq. 3 and Eq. 4 on every frame. At the end of this section, a summarize of all results obtained of variation of boundary conditions is presented. Each resulting image shows a representation of the average soot concentration through the flame in the path of the light. When the combustion reached a quasisteady state, the influence of ambient density, oxygen concentration, injection pressure, and ambient temperature was compared. Also, it's important to mention that energizing time selected for the injection event was $1300 \mu \mathrm{s}$ for both injectors, and it was kept constant throughout all tested conditions.

Each of the following images is divided into three parts. At the top of the image shows the mass soot evolution across the combustion flame, the color bar in the image goes from 0 to 0.3 in order to help to visualize the regions with low soot concentration, at the bottom-left of the image, shows the profile evolution (from right to left hand) soot formation along the central axis of the fuel jet from 30 to $85 \mathrm{~mm}$ of the nozzle tip, this distance corresponds with the visualization window. Finally, at the bottom-right of the image shows an angular evolution of the mass soot between - 20 and 20 degrees at $60 \mathrm{~mm}$ from the nozzle tip. In most images can be observed how the mass soot is higher at the flame front than in the rest of the flame, Skeen et al. [15] attributed this behavior to an increase in soot oxidation due to the fast entry of oxidizer behind the head of the spray.

Profile evolution of soot along the axis jet is characterized by three moments, at the first one can be appreciated an increase of the soot due to the domination of soot formation over soot oxidation. Then soot formation decreases when the axial distance increases due to fuel consumption and soot by the combustion process until reaching a peak where the soot formation and oxidation are in equilibrium. Finally, an overall decrease of the soot caused by the domination of the oxidation on soot formation. Liquid length effect on soot evolution can be appreciated at the first lengths of the evolution causing the optical thickness not to start from zero.

\subsubsection{Effect of ambient density}

Following the previous procedure, Fig. 14 presents an example of instantaneous $M_{\text {Soot }}$ variation using the injector PMI20 with the ambient density. Soot formation was tested for three different values of ambient density, 10,18 and $28 \mathrm{~kg} / \mathrm{m}^{3}$ and a fixed operating conditions of ambient temperature of $1000 \mathrm{~K}$, the oxygen concentration of $17 \%$, and injection pressure $200 \mathrm{MPa}$. The effect of density over the soot formation was found to be very consistent throughout the full test matrix such as Fig. 14 

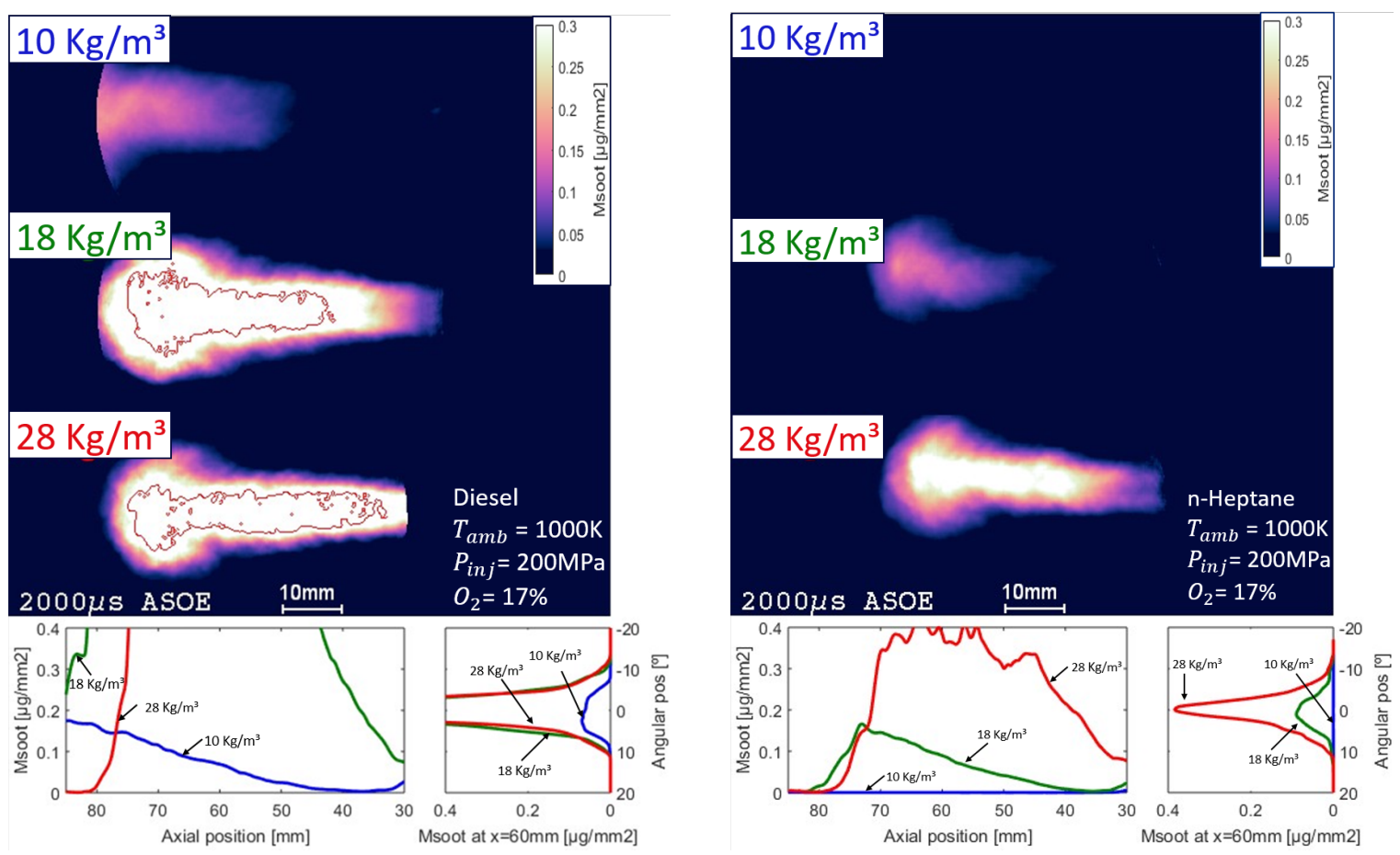

Fig. 14: Density effect on soot formation for $T_{a m b}=1000 \mathrm{~K}$ of $, p_{i n j}=200 \mathrm{MPa}, \mathrm{O}_{2}=17 \%$ and injector PMI20. Left: Diesel fuel. Right: n-Heptane fuel, soot was not detected at a density of $10 \mathrm{~kg} / \mathrm{m}^{3}$ or combustion happened far away from the injector tip. The red contour in the image shows the zones with saturation.

The largest concentration of soot was observed under a high density; similar trends were reported by [12, 13$]$. Fig. 14 shows a larger concentration of soot at a density of $28 \mathrm{~kg} / \mathrm{m}^{3}$, larger soot concentration blocks the passage of the LED light and give place to image saturation due to the large quantity of light coming from the soot formation. The red contour in the top image shows these zones with saturation. Also, low soot concentration was noted at the smallest value of the ambient density, as was expected and it is in agreeing with results found in the literature [9]. The first zone where the soot appears, it is modified by the density, Fig. 14. shows that soot formation process was moved near to injector tip when the ambient density was increased, [8, 26] explained this behavior as a result of two factors: lift-off length variation with the ambient density [43, 3] and the effect of the density in overall air entrainment about the quantity of the fuel injected.

Fig. 14-right, in terms of the value of the peak of $M_{\text {Soot }}$ for the n-Heptane case, there can be observed how the soot formation responds to the different values of the ambient density, variations are for both the amount of soot and the length where take place the soot formation, that was expected due to the difference of the lift-off length values with the variation of the ambient density, as shown in Fig. 12 Also, the $L O L$ at the density of $10 \mathrm{~kg} / \mathrm{m}^{3}$ was not detected, it was probably due to the combustion process occurred far away from the injector tip and it started under fuel-poor conditions. In addition, multiple factors that affect the soot production are dependent on the ambient density (i.e., liquid length, ignition delay, and lift-off length). Additionally, An increase in ambient density leads to a decrease of the amount of the air entrainment up to the lift-off length [45], which means richer conditions thus, increasing the soot formation through the flame.

\subsubsection{Effect of oxygen concentration}

Fig. 15 presents an example of oxygen concentration effects on soot formation for both n-Heptane and Diesel jets at equivalent test conditions. It shows an axial evolution of the mass soot value at the bottom-left image, where can be appreciated the decrease in soot formation when the oxygen concentration was lower. The behavior was as expected and it can be due to the reduction of soot formation rates by the lower combustion temperature, as well as the increase in the residence time, allowing more time for accumulation of soot [17]. 

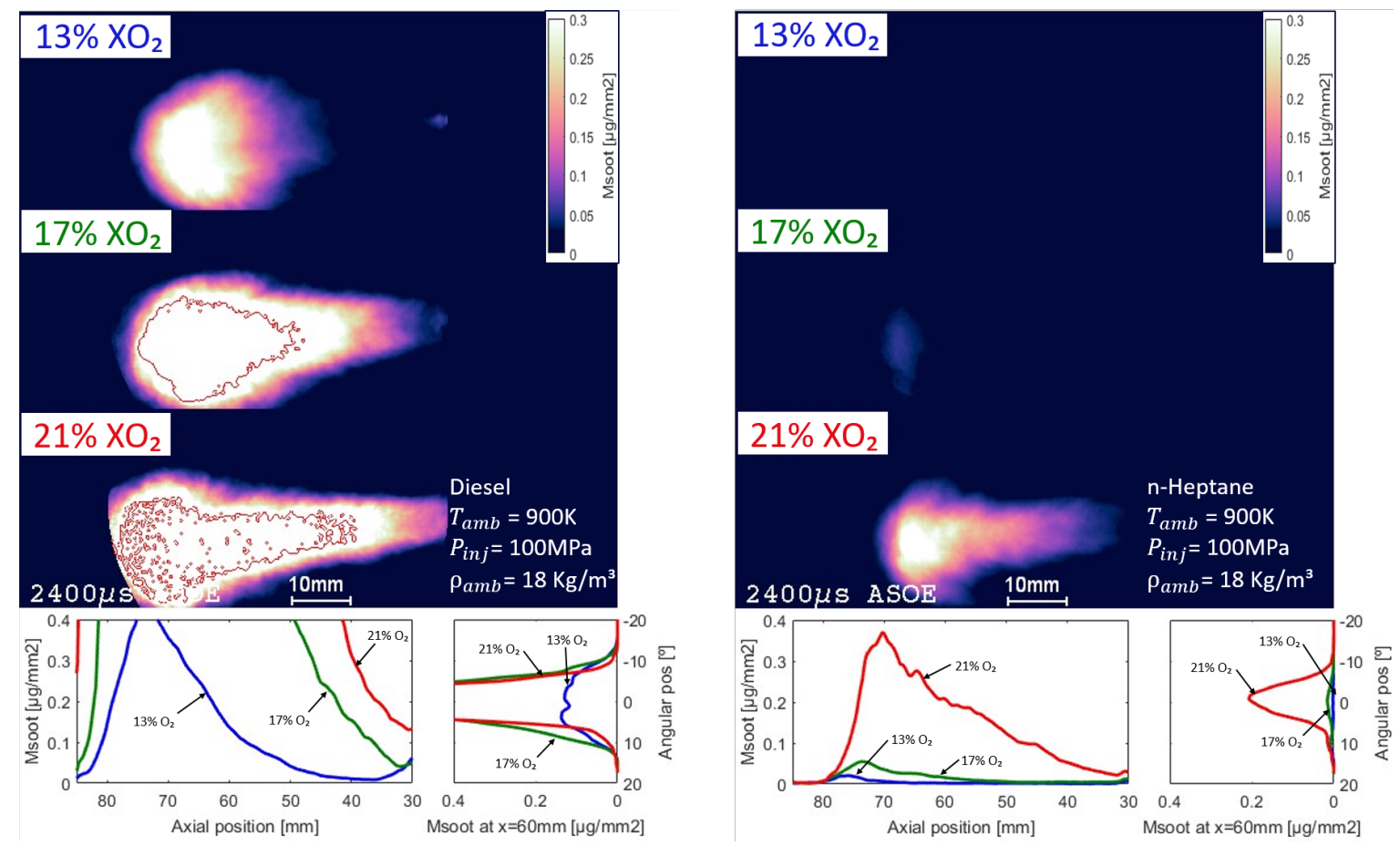

Fig. 15: Oxygen effect on soot formation at boundary conditions of $T_{a m b}=900 \mathrm{~K}, p_{i n j}=100 \mathrm{MPa}, \rho_{a m b}=18 \mathrm{~kg} / \mathrm{m}^{3}$ and injector PMI25. Left: Diesel fuel. Right: n-Heptane fuel.

Fig. 15 presents how the soot formation varies with different oxygen concentrations inside the vessel, at fixed conditions ( ambient density of $18 \mathrm{~kg} / \mathrm{m}^{3}$, the ambient temperature of $900 \mathrm{~K}$ and injection pressure of $100 \mathrm{MPa}$ ). This trend was found to be consistent along the complete test matrix. A difference in the distance of the first visualization of the soot was noted with oxygen concentration, which is as expected, Lift-off lengths are inversely proportional to oxygen concentration, as shows the Fig. 11 and they are consistent with the results reported by [4, 3]. Another possible cause for the downstream shift in the soot-forming region with the decrease in the oxygen concentration is the reduced rate of oxygen entrainment into the fuel jet, caused by the lower ambient oxygen concentration. Furthermore, increases in oxygen concentration cause soot formation rates to decrease because of lower combustion temperatures. However, the residence time in the soot-forming region increases because more time is required to mix with ambient oxygen [17].

In Fig. 15-right, can be appreciated that the soot formation in n-Heptane jet flame at oxygen concentartion of $17 \%$ occurs approximately at $65 \mathrm{~mm}$ from the injector tip. $L O L$ at equivalent conditions is $32 \mathrm{~mm}$ as shown in Fig. 13 resulting in a difference of $33 \mathrm{~mm}$ (with respect to $L O L$ ), this is consistency with the results presented in [17]. The reason of the distinct separations with respect to the injector tip is because of the soot formation takes a finite amount of time for soot precursors appear, then soot is formed downstream of the region of first heat release, which is started at lift-off length [19].

\subsubsection{Effect of injection pressure}

Fig. 16 presents the results of the evolution of the soot formation for selected test conditions. In this case, the injection pressure was evaluated in a range of $100 \mathrm{MPa}$ to $250 \mathrm{MPa}$ for the injector PMI25 at an ambient temperature of $1000 \mathrm{~K}$, an ambient density of $18 \mathrm{~kg} / \mathrm{m}^{3}$ and oxygen concentration of $17 \%$. Fig. 16 shows that an increase in injection pressure causes a large decrease in the soot formation for a fixed ambient condition (gas temperature and oxygen concentration), this trend was consistent for the whole test matrix for both injectors and fuels. Payri et al. [9] observed the same trend in their experimental results, when they changed the injection pressure in two single hole injectors. Analysis of the data was found that the peak of soot decreases linearly with increasing injection pressure coinciding with the results presented in [8].

According to the results presented in Fig. 13 and in the literature [3 26]. Lift-off length increases when increasing the injection pressure thus, higher $L O L$ implies a higher distance between the injector tip and the zone where soot appears [45], it gives place to increase the amount of air entrainment between the injector tip 
and the flame. Additionally, an increase of injection pressure causes an increase in injection velocity affecting the residence time in reacting region of the fuel jet on soot formation. Therefore, as the injection pressure increases, there is less time for soot formation inside the flame resulting in a decrease of $M_{\text {Soot }}$ [8, 45].
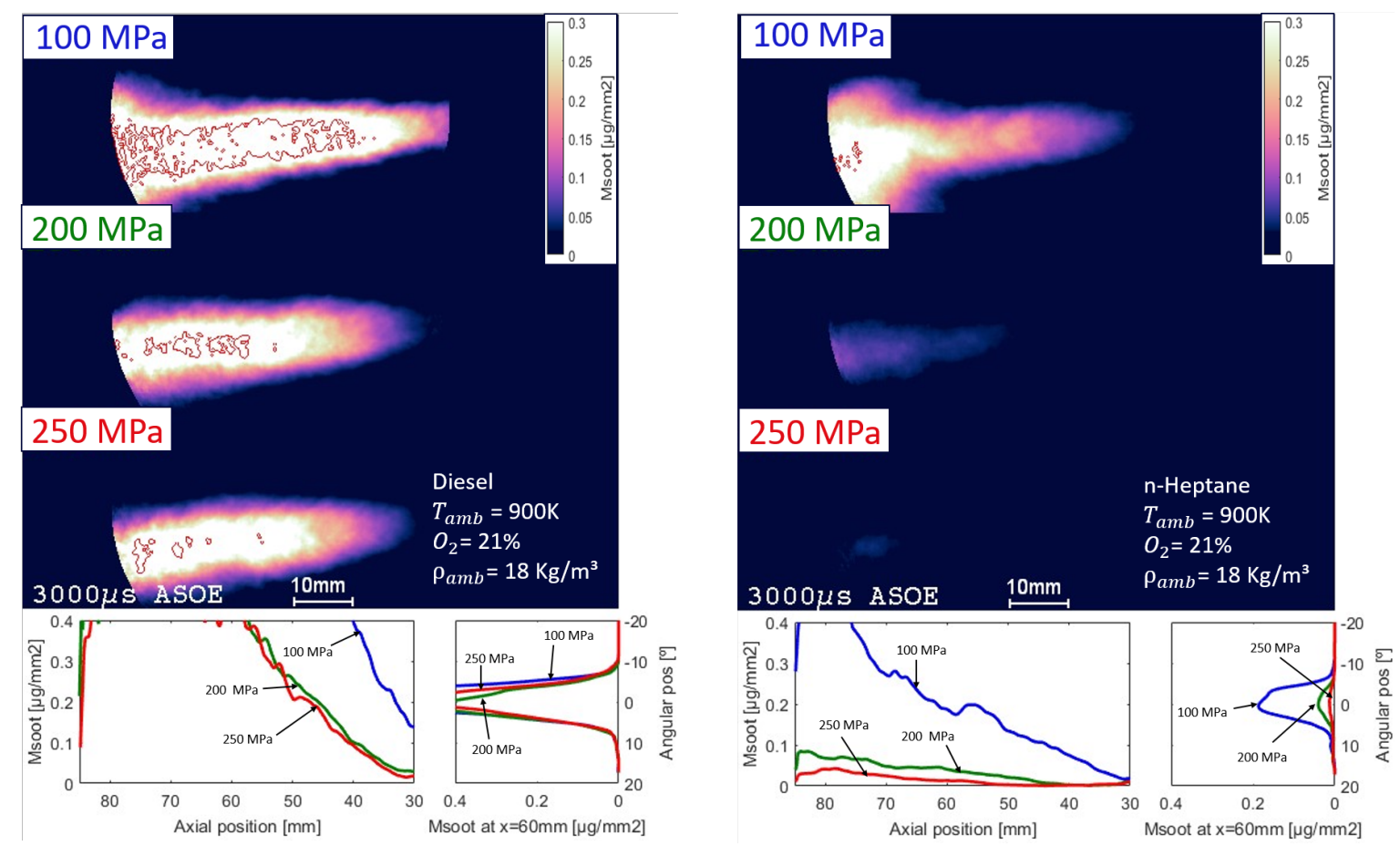

Fig. 16: Injection pressure effect on soot formation at test condtoion of $T_{a m b}=900 \mathrm{~K}, O_{2}=21 \%, \rho_{a m b}=18 \mathrm{~kg} / \mathrm{m}^{3}$ and injector PMI25. Left: Diesel fuel. Right: n-Heptane fuel.

\subsubsection{Effect of ambient temperature}

An example of the effects of the ambient gas temperature on soot evolution is presented in Fig. 17 for injector PMI20. The range of the ambient temperatures considered was $800 \mathrm{~K}$ up to $1000 \mathrm{~K}$, while the ambient density, injection pressure, and oxygen concentration were fixed in $28 \mathrm{~kg} / \mathrm{m}^{3}, 100 \mathrm{MPa}$ and $17 \%$ respectively. The trend observed here was consistent along the test matrix to both injectors and fuels. 

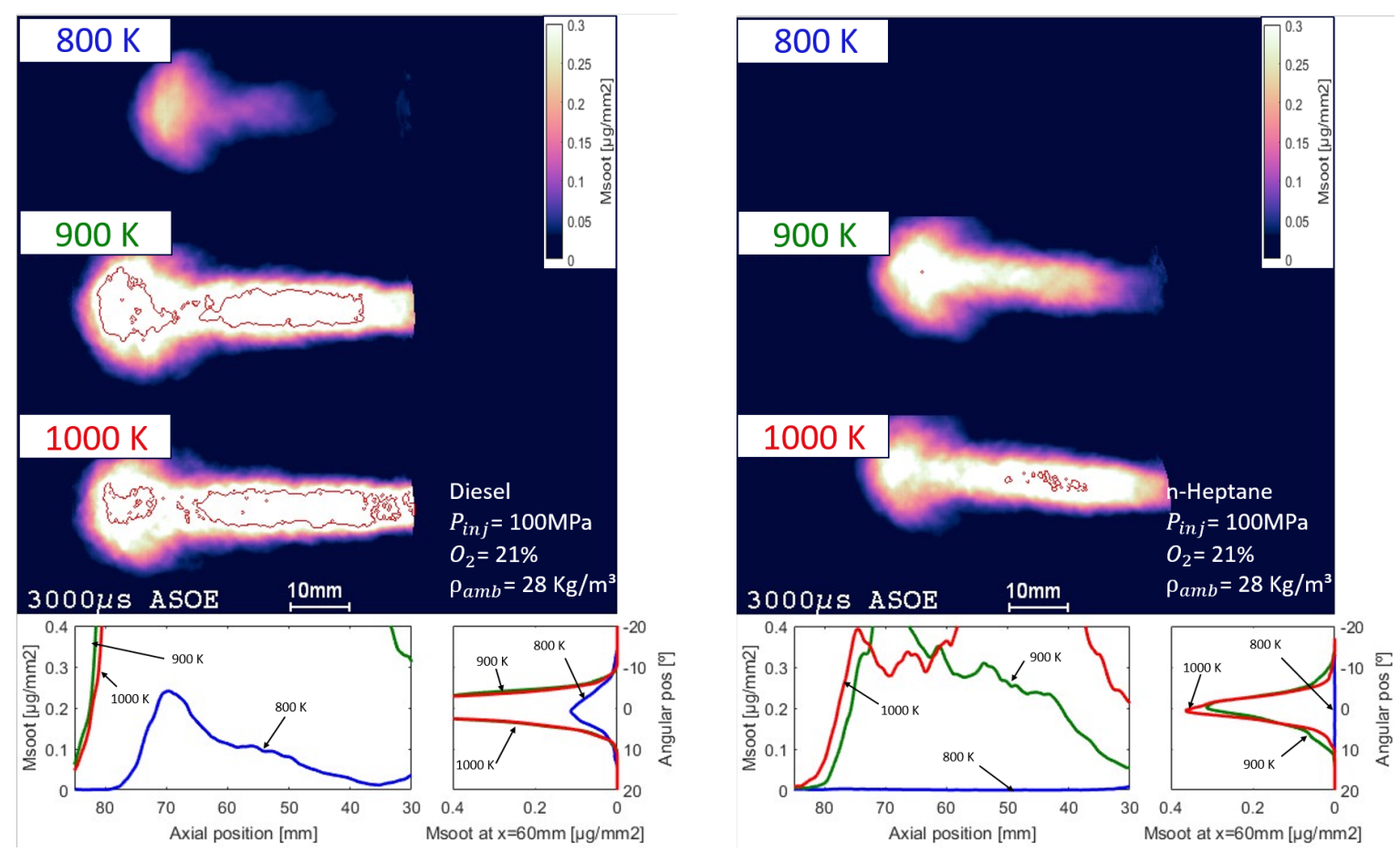

Fig. 17: Ambient temperature effect on soot formation at $p_{i n j}=100 \mathrm{MPa}, \mathrm{O}_{2}=17 \%, \rho_{a m b}=28 \mathrm{Kg} / \mathrm{m}^{3}$ and injector PMI20. Left: Diesel fuel. Right: n-Heptane fuel.

Fig. 17. clearly shows a serious variation of soot formation when increasing the ambient temperature. Pickett et al.[8], observed the same behavior in their results and they explained it as a result of two factors. The decrease of the Lift-off length when increasing the ambient gas temperature as shown in Fig. 12 where this effect was noted and the other factor is the reduction of the amount of air entrainment that occurred upstream of the liftoff length that means richer conditions. Skeen et al. [15], also observed this behavior. Aside from the effects of ambient temperature on $L O L$ and air entrainment, another factor that clearly influences the soot formation behavior of the fuel jet is the effect of the temperature on soot chemistry. It is well known that an increase in ambient temperature produces increased rates of both soot formation and soot oxidation chemistry [46].

Fig. 17-left shows a large $M_{\text {Soot }}$ profile within the Diesel flame, this is due to a high saturation promote by a high ambient gas temperature $(1000 \mathrm{~K})$, reaffirming the large influence the ambient gas temperature on soot formation, as was mentioned previously. Furthermore, another factor that contributed to soot behavior can be associated with a faster soot formation and a lack of significant oxidation chemistry in rich soot-forming regions [46].

Note in Fig. 17 that soot formation was not detected at an ambient gas temperature of $800 \mathrm{~K}$ for the injector PMI20, operating with n-Heptane fuel. However, a slight soot formation appears at a distance of $80 \mathrm{~mm}$ from the injector tip and a time after the start of energizing (ASOE) of $3500 \mu \mathrm{s}$, this does not correspond with the time presented in Fig. 17

\subsubsection{Effect of fuel and type injector}

Fig. 18 presents the effects of the fuel type and the differences between the two injectors used to perform the study of the soot formation. Fuels selected to carry out this experiment were Diesel and n-Heptane, in Fig 18 -left for injector PMI20 is notorious the quite differences between the two fuels used on soot production. Furthermore, can be appreciated the higher amount of soot produced with Diesel fuel than with n-Heptane at the same fixed ambient conditions. Diesel presents a zone with saturation, can be also noted that the soot formation started first and nearest to the injector tip (shorter $L O L$ ). This difference can be due to a sooting-tendency between n-Heptane and Diesel [17]. In addition, the higher-sooting propensity of Diesel affects the shape of the axial soot profile in several different ways. 

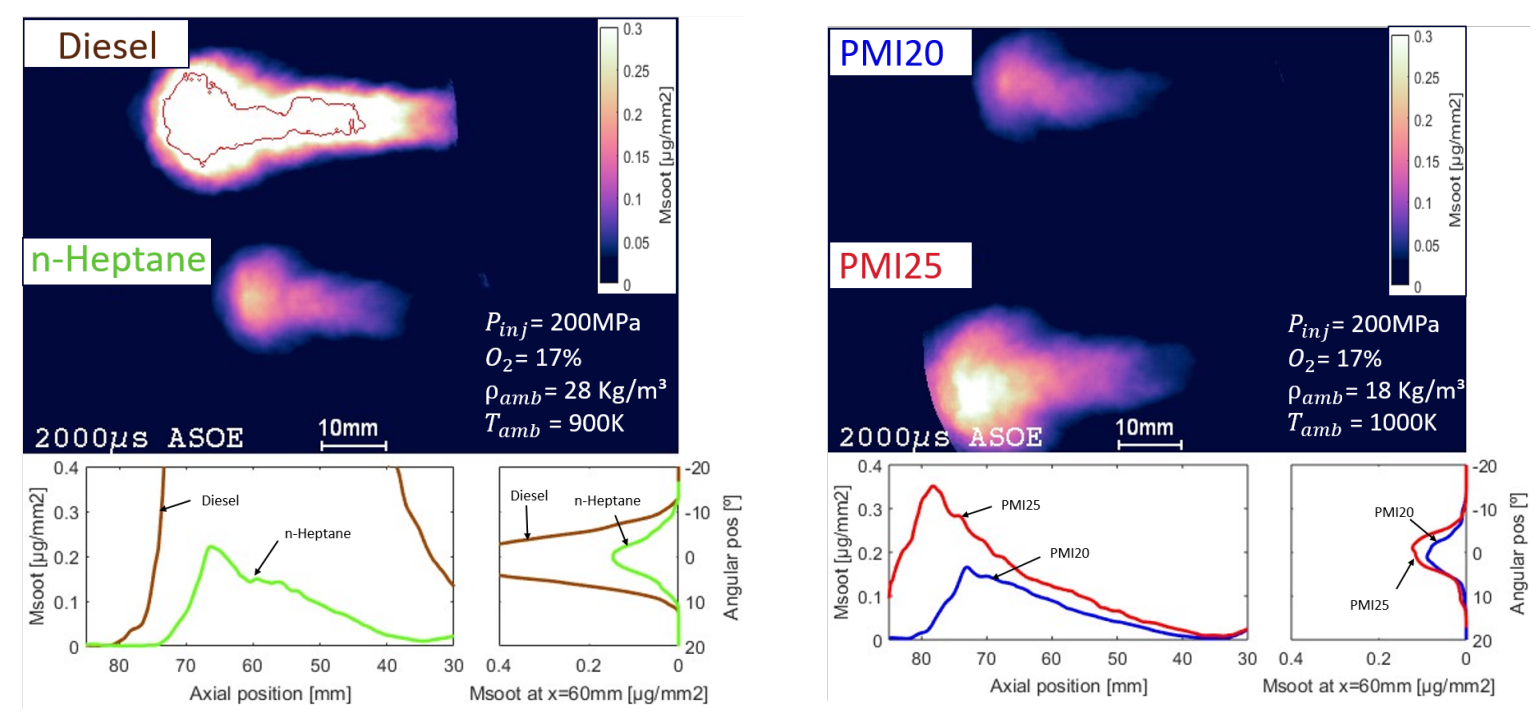

Fig. 18: Left: Fuel effect on soot formation at boundari contions of $p_{i n j}=200 \mathrm{MPa}, T_{a m b}=900 \mathrm{~K}, O_{2}=17 \%, \rho_{a m b}=28 \mathrm{~kg} / \mathrm{m}^{3}$ and injector PMI20. Right: Injector effect on soot formation for $p_{i n j}=200 \mathrm{MPa}$ of , $T_{a m b}=1000 \mathrm{~K}, O_{2}=17 \%$ and $\rho_{a m b}=18 \mathrm{~kg} / \mathrm{m}^{3}$ and n-Heptane fuel.

Fig. 18-right, presents the different of soot production during the injection event of both real multi-hole diesel injectors at a same energizing time, the behavior is as expected, due to the amount of soot is associated with the nozzle hole diameter at fixed ambient conditions (i.e., oxygen concentration, temperature, and density). This trend was consistent throughout the test matrix. Injector PMI25 has a nozzle hole diameter approximately $30 \mu \mathrm{m}$ higher than the injector PMI20, consequently, the injector with bigger hole diameter injects more amount of fuel at the same energizing time and produces more soot for the same operating conditions. Although, the lift-off length decreases slightly with a smaller orifice diameter as was shown in Fig 11 the orifice diameter has a strong impact on the amount of fuel-air mixing that occurs upstream of the lift-off length, the same trend was reported by [5]. 9 .

\subsubsection{Summary of mass soot formation}

In the previous analysis, were represented only a subset of results of the whole dataset. Fig. 19 summarizes the soot concentration in each test condition measured and following the same methodology, presented in section 3.3 Estimation of the amount of soot was made in a qualitative way for all results obtained through high-speed color diffused back illumination technique. Notation employed is as follow, in check mark symbol and green, the conditions where soot was not detected because of it was not formed or it was outside of the visual area (Test point conditions was measured but soot was not detected), ' $\mathrm{X}$ ' symbol, represents the test conditions that were not measured (This determination was based on the $L O L$ results and previous soot studies). A color bar shows the level of soot concentration. Red and a capital letter 'S', represents the conditions with a total extinction of the LED illumination due to the high amount of soot at these conditions. Finally, lowercase letter 's,' represents conditions with lower saturation.

Results presented in Fig. 19 are in good agreement with the trend found in the literature, increasing oxygen concentration, ambient gas temperature, ambient gas density, and decreasing injection pressure increases the soot formation [16, 14, 17, 9, 8, 18]. Injector PMI25 produces a higher soot formation than injector PMI20, section 3.3.5 explains the trend differences between them. Additionally, for Diesel fuel was performed a greater number of test point than n-Heptane, it due to the combustion of the n-Heptane jet occurs far away of the injector tip or the combustion begin under a fuel-poor condition. 

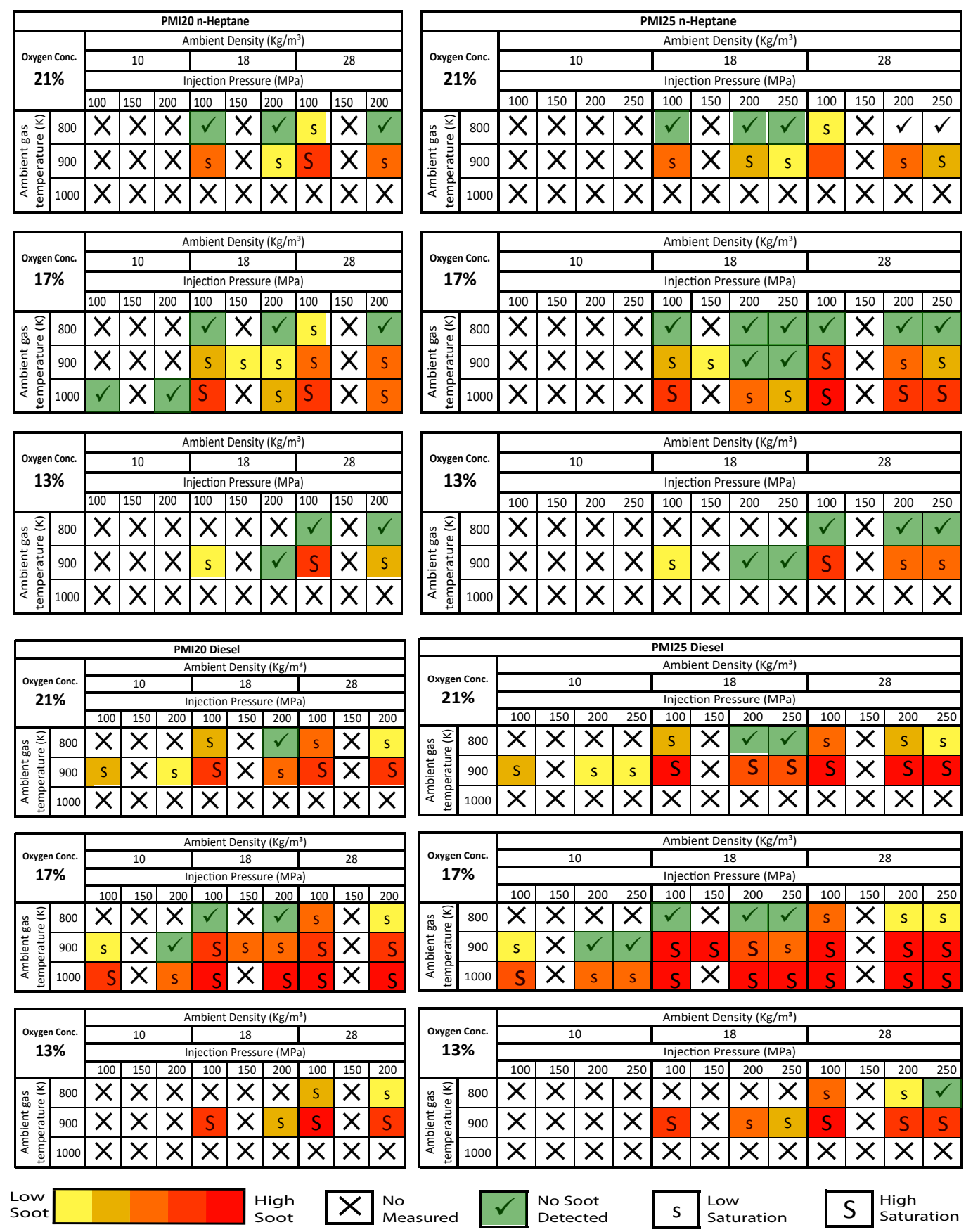

Fig. 19: Summary of results of the soot formation under different boundary conditions (whole test matrix), for both injectors, PMI20 and PMI25, performing with Diesel and n-Heptane.

\section{Conclusions}

A detailed experimental investigation of the phenomenon of combustion in real Diesel injectors was carried out evaluating $L O L, I D$ parameters and focusing mainly on soot formation. A new procedure was implemented to study the evolution of soot formation of two multi-hole nozzles, using high-speed color diffused back illumination technique. The measurements were performed in an optically accessible combustion vessel over a wide range of the test conditions (i.e., injection pressures, chamber densities, temperatures, oxygen concentrations). All experiments were performed for two different injectors and two fuels (diesel and n-Heptane). From the findings, 
it is possible to conclude:

\section{From the results}

- Ignition delays and lift-off lengths present a relationship between fuel ignition quality and lift-off length, throughout the whole test matrix, conditions with a shorter $I D$ also have a shorter $L O L$. Moreover, IDs and LOLs found in this study for the fuels used, follow the expected trends, ignition delays and lift-off lengths decrease with increasing ambient gas density or increasing ambient gas temperature.

- Results of $I D$ and $L O L$ are consistent with the trends found in the literature and results for soot formation applying the technique proposed are promising. Modifications made in the test rig to carry out the soot formation experiments with multi-hole injectors were satisfactory. Results obtained are motivating to performing future studies of soot formation with multi-hole injectors, in order to understand the behavior of combustion phenomena and allow to compare them with results reported for single-hole nozzles, and computational models.

- The results found show a large influence of the ambient gas temperature on soot formation. Soot formation was not detected at a temperature of $800 \mathrm{~K}$, it can due to non-ignition or the combustion take place outside of the view area. Also, the test conditions at high air temperatures present a high peak in the soot formation, this behavior is most likely due to the effect of reduced the lift-off length. Finally, must be noted that there is a relationship between lift-off length and the amount of soot formed for each fuel used to perform the experiments, this relationship was conserved with the parametric variations in the test conditions.

- Ambient gas density has a significant role in soot formation. Soot formation was not detected at an ambient density of $10 \mathrm{~kg} / \mathrm{m}^{3}$ inside the vessel. Soot formation increase with increasing ambient density was as expected, it due to a shortened the $L O L$, therefore combustion occurs closer to the injector tip and reduces the amount of air entrainment.

- Injection pressure has a direct effect on soot formation. Soot in the fuel jet decrease with increasing injection pressure, this behavior can be due to the result of combining two effects, an increase of $L O L$ and a decreased in the residence time in the combustion regions by the higher injection velocities.

- The largest soot formation was observed for injector PMI25 performing with Diesel fuel under critic ambient conditions: ambient temperature of $1000 \mathrm{~K}$, ambient density of $28 \mathrm{~kg} / \mathrm{m}^{3}$, injection pressure of $100 \mathrm{MPa}$ and oxygen concentration of $17 \%$ (the oxygen concentration of $21 \%$ was not tested at an ambient temperature of $1000 \mathrm{~K}$ because of the high amount of soot that reduces the ability of the Soot-DBI technique). This trend is the result of combined effects that reduce the lift-off length. Additionally, the orifice diameter has an important effect on soot formation by its direct influence in the relation air-fuel.

\section{From the back-illumination technique}

- Results obtained through Back-illumination technique were found to be consistent with the results reported in the literature for single hole injectors, and the trends followed the expected behavior.

- Back-illumination technique cannot determine with accuracy the soot concentration at boundary conditions inside the optical vessel that promote high soot formation, it due to the quite amount of soot in the jet flame that blocked the light from the LED thus, resulting in a reduction of the ability of the technique. Future works will be done using diffused back-illumination in multi-hole injectors, in order to explore more boundary conditions and fuels.

- The data gathered provides a basic comprehension of the soot formation process in multi-hole injector, as well as specific quantification useful for boundary conditions for CFD combustion models.

Finally, the present experimental work constitutes a starting point for futures works with multi-hole Diesel injectors. A wide range of test conditions was performed which is useful for understanding the soot formation in fuel jets from real Diesel injectors. Additionally, the experiments were performed for two fuels (Diesel and 
n-Heptane) and two different injectors (PMI20 and PMI25). Also, data provide an opportunity for the development and verification of soot and combustion models with multi-hole injectors and measurements available for comparison include an axial profile in spray axis and a radial profile at $60 \mathrm{~mm}$ from the injector tip.

\section{Acknowledgments}

This research has been funded by Jaguar Land Rover. The author Santiago Cardona thanks the Universitat Politècnica de València for his predoctoral contract (FPI-2016-S1), which is included within the framework of Programa de Apoyo para la Investigación y Desarrollo (PAID-01-2016). We would like to thank Omar Huerta for his collaboration during the measurement campaign and laboratory work.

\section{References}

[1] R. Colvile, E. Hutchinson, J. Mindell, R. Warren, The transport sector as a source of air pollution, Atmospheric Environment 35 (2001) 1537-1565. URL: http : / /WWW . sciencedirect . com/science/ article/pii/S1352231000005513 doi 10.1016/S1352-2310(00)00551-3

[2] U. S. E. P. A. USEPA, Air Quality Criteria for Particulate Matter October 2004, Volume 2, Air Quality Criteria for Particulate Matter II (2004) 1148. URL: file:///C:/Users/La\{ \unhbox

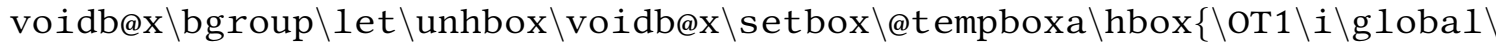
mathchardef $\backslash$ accent@spacefactor $\backslash$ spacefactor $\} \backslash$ accent $19 \backslash 0 T 1 \backslash i \backslash$ egroup $\backslash$ spacefactor $\backslash$ accent@spacefactor $\}$ ssa/Downloads/VOL $\{-\} \operatorname{III}\{-\}$ FINAL $\{-\} \operatorname{PM}\{-\}$ AQCD $\{-\} O C T 2004$.PDF

[3] R. Payri, F. J. Salvador, J. Gimeno, J. E. Peraza, Experimental study of the injection conditions influence over n-dodecane and diesel sprays with two ECN single-hole nozzles. Part II: Reactive atmosphere, Energy Conversion and Management 126 (2016) 1157-1167. URL: http: / /dx . doi .org/10 .1016/j . enconman.2016.07.079 doi $10.1016 / j$.enconman.2016.07.079.

[4] R. Payri, F. J. Salvador, J. Manin, A. Viera, Diesel ignition delay and lift-off length through different methodologies using a multi-hole injector, Applied Energy 162 (2016) 541-550. URL: http:// linkinghub.elsevier.com/retrieve/pii/S0306261915013549 doi $10.1016 / \mathrm{j}$. apenergy.2015.10.118

[5] L. M. Pickett, D. L. Siebers, Orifice Diameter Effects on Diesel Fuel Jet Flame Structure, Journal of Engineering for Gas Turbines and Power 127 (2005) 187. URL: http://gasturbinespower. asmedigitalcollection.asme.org/article.aspx?articleid=1422454 doi 10 . $1115 / 1.1760525$

[6] L. M. Pickett, D. L. Siebers, C. A. Idicheria, Relationship Between Ignition Processes and the Lift-Off Length of Diesel Fuel Jets, SAE Paper 2005-01-3843 (2005).

[7] B. Higgins, D. L. Siebers, Measurement of the Flame Lift-Off Location on DI Diesel Sprays Using OH Chemiluminescence, SAE Paper 2001-01-0918 (2001).

[8] L. M. Pickett, D. L. Siebers, Soot in diesel fuel jets: effects of ambient temperature, ambient density, and injection pressure, Combustion and Flame 138 (2004) 114-135. URL: ht tp: //WWW . sciencedirect.

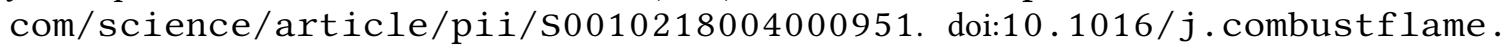
2004.04 .006

[9] F. Payri, J. V. Pastor, J. M. Garcia-Oliver, J. M. Pastor, Contribution to the application of twocolour imaging to diesel combustion, Measurement Science and Technology 18 (2007) 2579-2598. URL: $\quad$ http://stacks .iop.org/0957-0233/18/i=8/a=034 ?key=crossref. f0eddcd74c5f24a694ef4ed82079052a doi 10.1088/0957-0233/18/8/034

[10] K. Nakakita, M. Nagaoka, T. Fujikawa, K. Ohsawa, S. Yamaguchi, Photographic and Three Dimensional Numerical Studies of Diesel Soot Formation Process, SAE Technical Paper 902081 (1990). URL: http : //papers.sae.org/902081/ doi 10.4271/902081 
[11] D. R. Snelling, K. A. Thomson, G. J. Smallwood, Ö. L. Gülder, Two-dimensional imaging of soot volume fraction in laminar diffusion flames, Applied Optics 38 (1999) 2478. URL: https: //www. osapublishing.org/abstract.cfm?URI=ao-38-12-2478 doi $10.1364 / \mathrm{AO} .38 .002478$

[12] Y. Xu, C.-f. F. Lee, Forward-illumination light-extinction technique for soot measurement, Applied Optics 45 (2006) 2046. URL: https : / / wWW . osapublishing . org/abstract . cfm?URI= ao-45-9-2046 doi 10.1364/AO.45.002046

[13] K. A. Thomson, M. R. Johnson, D. R. Snelling, G. J. Smallwood, Diffuse-light two-dimensional line-ofsight attenuation for soot concentration measurements, Applied Optics 47 (2008) 694. URL: https: // WwW. osapublishing.org/abstract.cfm?URI=ao-47-5-694 doi 10.1364/AO.47. 000694

[14] J. Manin, S. A. Skeen, L. M. Pickett, Two-color diffused back-illumination imaging as a diagnostic for time-resolved soot measurements in reacting sprays, SAE Int. J. Engines 6 (2013) 1908-1921. URL: http://saeeng.saejournals.org/content/6/4/1908.short doi $10.4271 /$ 2013-01-2548

[15] S. A. Skeen, J. Manin, K. Dalen, L. M. Pickett, Extinction-based Imaging of Soot Processes over a Range of Diesel Operating Conditions, in: 8th US National Combustion Meeting, Utah, USA, 2013, pp. 1-13. URL: http://wWw. che.utah.edu/\{ \}sutherland/USCI2013/PAPERS/ 2C10-070IC-0355.pdf

[16] M. Bardi, G. Bruneaux, A. Nicolle, O. Colin, Experimental Methodology for the Understanding of SootFuel Relationship in Diesel Combustion: Fuel Characterization and Surrogate Validation, SAE Technical Paper 2017-01-0721 (2017). URL: http://papers.sae.org/2017-01-0721/ doi 10.4271/ 2017-01-0721

[17] C. A. Idicheria, L. M. Pickett, Soot formation in Diesel combustion under high-EGR conditions, SAE Technical Paper 2005-01-3834 (2005). doi 10.4271/2005-01-3834

[18] J. V. Pastor, J. M. Garcia-Oliver, R. Novella, T. Xuan, Soot Quantification of Single-Hole Diesel Sprays by Means of Extinction Imaging, SAE International Journal of Engines 8 (2015) 2068-2077. doi 10 .4271/ 2015-24-2417

[19] L. M. Pickett, D. L. Siebers, Soot Formation in Diesel Fuel Jets Near the Lift-Off Length, International Journal of Engine Research 7 (2006) 103-130. URL: http://journals . sagepub.com/doi/10.1243/ $146808705 \times 57793$ doi $10.1243 / 146808705 \times 57793$

[20] J. Gimeno, P. Martí-Aldaraví, M. Carreres, J. E. Peraza, Effect of the nozzle holder on injected fuel temperature for experimental test rigs and its influence on diesel sprays, International Journal of Engine Research 19 (2018) 374-389. URL: http://journals.sagepub.com/doi/10.1177/ 1468087417751531 doi $10.1177 / 1468087417751531$

[21] R. Payri, J. Gimeno, J. P. Viera, A. H. Plazas, Needle lift profile influence on the vapor phase penetration for a prototype diesel direct acting piezoelectric injector, Fuel 113 (2013) 257-265. URL: http : //WWW . sciencedirect.com/science/article/pii/s0016236113004699http://dx. doi.org/10.1016/j.fuel.2013.05.057 doi $10.1016 / j$.fuel.2013.05.057

[22] R. Payri, J. M. Garcia-Oliver, M. Bardi, J. Manin, Fuel temperature influence on diesel sprays in inert and reacting conditions, Applied Thermal Engineering 35 (2012) 185-195. URL: doi: $10.1016 / \mathrm{j}$. applthermaleng.2011.10.027http://linkinghub.elsevier.com/retrieve/ pii/S1359431111005655 doi $10.1016 / \mathrm{j}$. applthermaleng.2011.10.027.

[23] R. Payri, F. J. Salvador, J. Gimeno, J. de la Morena, Effects of nozzle geometry on direct injection diesel engine combustion process, Applied Thermal Engineering 29 (2009) 2051-2060. URL: http://dx.doi.org/10.1016/j.applthermaleng.2008.10.009 doi $10.1016 / \mathrm{j}$. applthermaleng.2008.10.009 
[24] S. Thomas, Enhanced oil recovery-an overview, Oil \& Gas Science and Technology-Revue ... 63 (2008) 919. URL:http://ogst. ifpenergiesnouvelles.fr/articles/ogst/abs/2008/01/ ogst07042/ogst07042.html doi $10.2516 /$ ogst.

[25] P. M. Lillo, L. M. Pickett, H. Persson, O. Andersson, S. Kook, Diesel Spray Ignition Detection and Spatial/Temporal Correction, SAE Paper 2012-01-1239 (2012) 1-21. doi 10.4271/2012-01-1239

[26] D. L. Siebers, B. Higgins, Flame Lift-Off on Direct-Injection Diesel Sprays Under Quiescent Conditions, SAE Technical Paper 2001-01-0530 (2001).

[27] L. M. Pickett, J. Manin, C. L. Genzale, D. L. Siebers, M. P. B. Musculus, C. A. Idicheria, Relationship Between Diesel Fuel Spray Vapor Penetration/Dispersion and Local Fuel Mixture Fraction, SAE International Journal of Engines 4 (2011) 764-799. URL: http://WWW. scopus. com/inward/record. url ?eid=2-s2 . 0-79959541966 $\{\&\}$ partner ID $=40\{\&\} \mathrm{md} 5=$ e747b89db62877f828b8c41c08454dd4 doi 10.4271/2011-01-0686

[28] N. Peters, Turbulent Combustion, Cambridge University Press, Cambridge, 2000. URL: http://ebooks . cambridge.org/ref/id/CBO9780511612701 doi 10.1017/ CBO9780511612701

[29] R. Payri, G. Bracho, P. Marti-Aldaravi, A. Viera, Near field visualization of diesel spray for different nozzle inclination angles in non-vaporizing conditions, Atomization and Sprays 27 (2017) 251-267. doi $10.1615 /$ AtomizSpr. 2017017949

[30] R. Payri, F. J. Salvador, J. Gimeno, J. P. Viera, Experimental analysis on the influence of nozzle geometry over the dispersion of liquid n-dodecane sprays, Frontiers in Mechanical Engineering 1 (2015) 1-10. URL: http://journal.frontiersin.org/Article/10.3389/fmech.2015.00013/ abstract doi $10.3389 /$ fmech.2015.00013

[31] R. Payri, J. Gimeno, S. Cardona, S. Ayyapureddi, Measurement of Soot Concentration in a Prototype Multi-Hole Diesel Injector by High-Speed Color Diffused Back Illumination Technique, in: SAE Technical Paper 2017-01-2255, 2017, p. 11. URL: http://papers.sae.org/2017-01-2255/ doi $10.4271 / 2017-01-2255$

[32] J. Manin, L. M. Pickett, S. A. Skeen, Toward quantitative spray measurements using high-performance high-speed video cameras, ILASS Americas 2016 (2016) 511-518.

[33] T. Williams, C. Shaddix, K. Jensen, J. Suo-Anttila, Measurement of the dimensionless extinction coefficient of soot within laminar diffusion flames, International Journal of Heat and Mass Transfer 50 (2007) 1616-1630. doi $10.1016 / j$.ijheatmasstransfer.2006.08.024

[34] U. O. Koylu, G. M. Faeth, Optical Properties of Overfire Soot in Buoyant Turbulent Diffusion Flames at Long Residence Times, Journal of Heat Transfer 116 (1994) 152. URL: http://heattransfer. asmedigitalcollection . asme.org/article. aspx?articleid=1441600 doi 10 . $1115 / 1.2910849$

[35] M. Y. Choi, G. W. Mulholland, A. Hamins, T. Kashiwagi, Comparisons of the soot volume fraction using gravimetric and light extinction techniques, Combustion and Flame 102 (1995) 161169. URL: http://linkinghub.elsevier.com/retrieve/pii/001021809400282W doi $10.1016 / 0010-2180(94) 00282-\mathrm{W}$.

[36] J. Cao, Z. He, B. Li, W. Zhong, M. Wang, Study of the soot quantification for two-stage injection of diesel in a constant-volume combustion chamber, in: ILASS-Europe 2017, 28th Conference on Liquid Atomization and Spray Systems, Valencia (Spain), 2017, p. 8. URL: http ://dx . doi.org/10 .4995/ILASS2 017. 2017.4739 doi $10.4995 /$ ILASS2017.2017.4739.

[37] P. J. M. Frijters, R. G. M. Vallen, L. Somers, C. C. M. Luijten, R. S. G. Baert, Fuel Effects on Illumination Ignition Delay and Soot Lift-off Length in Diesel Combustion D . A . \& Control Common Rail Pump CR Injector Thimble, in: Proceedings of the European Combustion Meeting 2007, 2007, pp. 1-6. 
[38] J. P. Viera, Experimental study of the effect of nozzle geometry on the performance of direct-injection diesel sprays for three different fuels, Ph.D. thesis, Universitat Politècnica de València, 2017.

[39] J. V. Pastor, J. M. García-Oliver, J. J. López, W. Vera-Tudela, An experimental study of the effects of fuel properties on reactive spray evolution using Primary Reference Fuels, Fuel 163 (2016) 260-270. URL: http: // dx.doi.org/10.1016/j.fuel.2015.09.064 doi $10.1016 / j$.fuel.2015.09.064

[40] B. Higgins, D. L. Siebers, A. Aradi, Diesel-Spray Ignition and Premixed-Burn Behavior, SAE Technical Paper 2000-01-0940 (2000).

[41] J. Benajes, R. Payri, M. Bardi, P. Martí-aldaraví, Experimental characterization of diesel ignition and lift-off length using a single-hole ECN injector, Applied Thermal Engineering 58 (2013) 554-563. URL: http: //wWW.sciencedirect.com/science/article/pii/S1359431113003153http: //dx.doi.org/10.1016/j.applthermaleng.2013.04.044. doi $10.1016 / \mathrm{j}$. applthermaleng.2013.04.044

[42] J. B. Heywood, Internal combustion engine fundamentals, McGraw-Hill, New York, NY, 1988.

[43] R. Payri, J. P. Viera, Y. Pei, S. Som, Experimental and numerical study of lift-off length and ignition delay of a two-component diesel surrogate, Fuel 158 (2015) 957-967. URL: http : // linkinghub . elsevier.

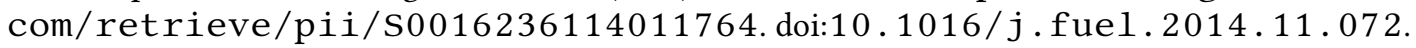

[44] R. Payri, J. P. Viera, V. Gopalakrishnan, P. G. Szymkowicz, The effect of nozzle geometry over internal flow and spray formation for three different fuels, Fuel 183 (2016) 20-33. URL: http:// linkinghub.elsevier.com/retrieve/pii/s0016236116304938 doi $10.1016 / \mathrm{j}$. fuel.2016.06.041

[45] J. M. Garcia-Oliver, Aportaciones al estudio del proceso de combustión turbulenta de chorros en motores Diesel de inyección directa, Ph.D. thesis, E.T.S. Ingenieros Industriales. Universidad Politécnica de Valencia, Valencia, 2004.

[46] I. Glassman, Soot formation in combustion processes, Symposium (International) on Combustion 22 (1989) 295-311. URL: https://wWw. sciencedirect.com/science/article/pii/ S0082078489800360 doi 10.1016/S0082-0784(89)80036-0 